\title{
Distinct Determinants of Sparse Activation during Granule Cell Maturation
}

\author{
Cristina V. Dieni, ${ }^{1}$ Angela K. Nietz, ${ }^{1}$ Roberto Panichi, ${ }^{2}$ Jacques I. Wadiche, ${ }^{1}$ and Linda Overstreet-Wadiche ${ }^{1}$ \\ ${ }^{1}$ McKnight Brain Institute and Department of Neurobiology, University of Alabama at Birmingham, Birmingham, Alabama 35294, and ${ }^{2}$ Department of \\ Internal Medicine, Section of Human Physiology, University of Perugia, 06126 Perugia, Italy
}

Adult neurogenesis continually produces a small population of immature granule cells (GCs) within the dentate gyrus. The physiological properties of immature GCs distinguish them from the more numerous mature GCs and potentially enables distinct network functions. To test how the changing properties of developing GCs affect spiking behavior, we examined synaptic responses of mature and immature GCs in hippocampal slices from adult mice. Whereas synaptic inhibition restricted GC spiking at most stages of maturation, the relative influence of inhibition, excitatory synaptic drive, and intrinsic excitability shifted over the course of maturation. Mature GCs received profuse afferent innervation such that spiking was suppressed primarily by inhibition, whereas immature GC spiking was also limited by the strength of excitatory drive. Although the input resistance was a reliable indicator of maturation, it did not determine spiking probability at immature stages. Our results confirm the existence of a transient period during GC maturation when perforant path stimulation can generate a high probability of spiking, but also reveal that immature GC excitability is tempered by functional synaptic inhibition and reduced excitatory innervation, likely maintaining the sparse population activity observed in vivo.

\section{Introduction}

A hallmark of the dentate gyrus (DG) is the continuous production of new neurons. Newly generated granule cells (GCs) progress through a series of functional stages during which their intrinsic electrophysiological properties and synaptic connectivity are distinct from pre-existing mature GCs (Ambrogini et al., 2004; Espósito et al., 2005; Overstreet Wadiche et al., 2005; Ge et al., 2006). A few weeks after cell birth, immature GCs receive excitatory synapses from the perforant path and also have high intrinsic excitability, allowing action potential (AP) threshold to be reached in response to only a small number of excitatory inputs (Schmidt-Hieber et al., 2004; Mongiat et al., 2009). Thus, perforant path stimulation generates spiking $(S)$ in a greater percentage of immature GCs compared with mature GCs (MarínBurgin et al., 2012). However, it is not clear how inhibition, excitation, and intrinsic excitability dictate the spiking probability at progressive stages of GC maturation.

The DG uses sparse population coding, wherein only a small fraction of GCs are activated by physiological stimuli (for review, see Piatti et al., 2013). GABA receptor-mediated synaptic inhibition is a key component of sparse GC activation and the transformation of cortical activity into place fields (Coulter and

Received May 28, 2013; revised 0ct. 16, 2013; accepted 0ct. 20, 2013.

Author contributions: C.V.D., J.I.W., and L.O.-W. designed research; C.V.D. and A.K.N. performed research; C.V.D., A.K.N., R.P., J.I.W., and L.O.-W. analyzed data; C.V.D., J.I.W., and L.O.-W. wrote the paper.

This work was supported by National Institutes of Health Grants R01NS064025 (L.O.-W.), NS065920 (J.I.W.), and P30 NS047466. We thank Drs. Matt Jones and Laura Ewell for helpful comments on an earlier version of the manuscript, and members of the Wadiche laboratories for helpful comments throughout this project.

Correspondence should be addressed to either Dr. Jacques I. Wadiche or Dr. Linda Overstreet-Wadiche, University of Alabama at Birmingham, Department of Neurobiology, 1825 University Boulevard, Birmingham, AL 35294. E-mail: jwadiche@uab.edu or Iwadiche@uab.edu.

DOI:10.1523/JNEUROSCI.2289-13.2013

Copyright $\odot 2013$ the authors $\quad 0270-6474 / 13 / 3319131-12 \$ 15.00 / 0$
Carlson, 2007; de Almeida et al., 2009; Rennó-Costa et al., 2010; Yu et al., 2013). GABAergic mechanisms also have important trophic functions in adult neurogenesis, promoting morphological and synaptic integration of newborn GCs that are depolarized by GABA due to elevated intracellular $\left[\mathrm{Cl}^{-}\right.$] (Tozuka et al., 2005; Ge et al., 2006; Dieni et al., 2012; Chancey et al., 2013). By 4 weeks after $\mathrm{GC}$ birth, the intracellular $\left[\mathrm{Cl}^{-}\right]$has switched to mature levels (Ge et al., 2006; Marín-Burgin et al., 2012), yet synaptic responses and spiking induced by perforant path stimulation appears to be insensitive to blockade of $\mathrm{GABA}_{\mathrm{A}}$ receptors (Wang et al., 2000; Li et al., 2012; Marín-Burgin et al., 2012). The surprising lack of functional inhibition is attributed to the slow rise times of IPSCs that minimize inhibition at the time of spike initiation (Marín-Burgin et al., 2012). Consistent with this idea, developing GCs receive GABAergic synapses from interneurons like Ivy/ Neurogliaform cells that generate slow dendritic conductances before innervation by perisomatic-targeting basket cells that generate IPSCs with rapid kinetics (Espósito et al., 2005; Overstreet Wadiche et al., 2005; Laplagne et al., 2007; Markwardt et al., 2011). Dendritic (slow) and somatic (fast) inhibition typically control synaptic integration and spike output, respectively, and both contribute to oscillatory behavior and patterned spike activity (Freund and Buzsáki, 1996; Stokes and Isaacson, 2010; Royer et al., 2012). Fast and slow IPSCs develop during the first 4 weeks following GC birth (Espósito et al., 2005; Marín-Burgin et al., 2012) and synaptic inhibition within the DG is robust (Ewell and Jones, 2010; Yu et al., 2013); thus, we predicted that GABAergic inhibition restricts spiking even at early stages of GC development.

Here we examine the role of excitation and inhibition in GC spiking at progressive developmental stages, focusing primarily on time points when adult-generated GCs have been shown to make unique contributions to DG function ( $\sim 4$ weeks; Arruda- 
Carvalho et al., 2011; Gu et al., 2012). Our results confirm that under some conditions immature GCs are more likely than mature GCs to generate spikes in response to perforant path stimulation, but we also find that spiking of immature GCs is limited by functional synaptic inhibition and reduced excitatory innervation. Together, our results suggest that distinct mechanisms maintain low levels of spiking in GCs at all stages of maturation.

\section{Materials and Methods}

We used 5- to 8-week-old wild-type, GAD67GFP reporter mice (Zhao et al., 2010) and Nestin-CreER ${ }^{\mathrm{T} 2}$ mice (Lagace et al., 2007) crossed with R26R-TdTomato reporter mice (stock \#007914, Jackson Laboratories), all maintained on the C57BL/6J background. Mice of either sex were maintained in standard housing. All animal procedures followed the United States Public Health Service Guide for the Care and Use of Laboratory Animals, and were approved by the University of Alabama at Birmingham Institutional Animal Care and Use Committee.

Nestin-CreER ${ }^{\mathrm{T} 2}$ reporter mice were injected with tamoxifen $(180 \mathrm{mg} / \mathrm{kg} / \mathrm{d}$, i.p.) for $5 \mathrm{~d}$ dissolved in $10 \% \mathrm{EtOH} / 90 \%$ sunflower oil (Lagace et al., 2007). Tamoxifen treatment was typically initiated at weaning to allow sufficient numbers of labeled cells. Mice were anesthetized and perfused intracardially with ice-cold modified artificial CSF containing the following (in $\mathrm{mm}$ ): 110 choline chloride, 26 D-glucose, $2.5 \mathrm{MgCl}_{2}, 2.5 \mathrm{KCl}, 1.25 \mathrm{Na}_{2} \mathrm{PO}_{4}$, $0.5 \mathrm{CaCl}_{2}, 1.3 \mathrm{Na}$-ascorbate, $3 \mathrm{Na}$-pyruvate, and $25 \mathrm{NaHCO}_{3}$, bubbled with $95 \% \mathrm{O}_{2} / 5 \%$ $\mathrm{CO}_{2}$. The brain was removed and $350-\mu \mathrm{m}-$ thick horizontal slices were prepared using a vibratome (Vibratome 3000EP). Slices were incubated at $37^{\circ} \mathrm{C}$ for $\sim 30 \mathrm{~min}$ in recording solution containing the following (in $\mathrm{mM}$ ): 125 $\mathrm{NaCl}, 2.5 \mathrm{KCl}, 1.25 \mathrm{Na}_{2} \mathrm{PO}_{4}, 2 \mathrm{CaCl}_{2}, 1 \mathrm{MgCl}_{2}$, $25 \mathrm{NaHCO}_{3}$, and $25 \mathrm{D}$-glucose bubbled with $95 \% \mathrm{O}_{2} / 5 \% \mathrm{CO}_{2}$; and then transferred to room temperature in the same solution. Patch pipettes were filled with the following ( $\mathrm{mM}): 150$ K-gluconate, $1 \mathrm{MgCl}_{2}, 1.1 \mathrm{EGTA}, 5$ HEPES, and 10 phosphocreatine, $\mathrm{pH} 7.2$ and 300 mOsm. In some experiments, we used a pipette internal with the following (mM): $120 \mathrm{~K}$-gluconate, $15 \mathrm{KCl}, 4 \mathrm{MgCl}_{2}, 0.1$ EGTA, 10 HEPES, $4 \mathrm{Mg}$ ATP, $0.3 \mathrm{Na}_{3} \mathrm{GTP}$, and 7 phosphocreatine, $\mathrm{pH}$ 7.4 and $300 \mathrm{mOsm}$. Biocytin (0.2\%) was included in the pipette in some experiments for morphological visualization after recording, using streptavidin conjugated to Alexa Fluor 647 (Invitrogen). Synaptic responses were evoked using two patch pipettes filled with extracellular solution $(100 \mu \mathrm{s} ; 100-300 \mu \mathrm{A})$. All recordings were performed at room temperature and at a holding potential of $-70 \mathrm{mV}$. Voltages were not corrected for junction potentials, and currents were filtered at $2 \mathrm{kHz}$ and sampled at $10 \mathrm{kHz}$ (MultiClamp 700A; Molecular Devices). Series resistance was uncompensated $(10-25 \mathrm{M} \Omega)$, and experiments were discarded if the resistance changed $(>20 \%)$. All responses were analyzed using Axograph X (AxoGraph Scientific). Input resistance $\left(R_{\text {input }}\right)$ was obtained from hyperpolarizing current injections of $20 \mathrm{pA}$ for mature GCs and $10 \mathrm{pA}$ for immature GCs. Action potential threshold was detected when the slope exceeded $10 \mathrm{mV} / \mathrm{ms}$. Spike rise time (20-80\%) was measured from spike onset. Cell-attached recordings were performed with a

C

G
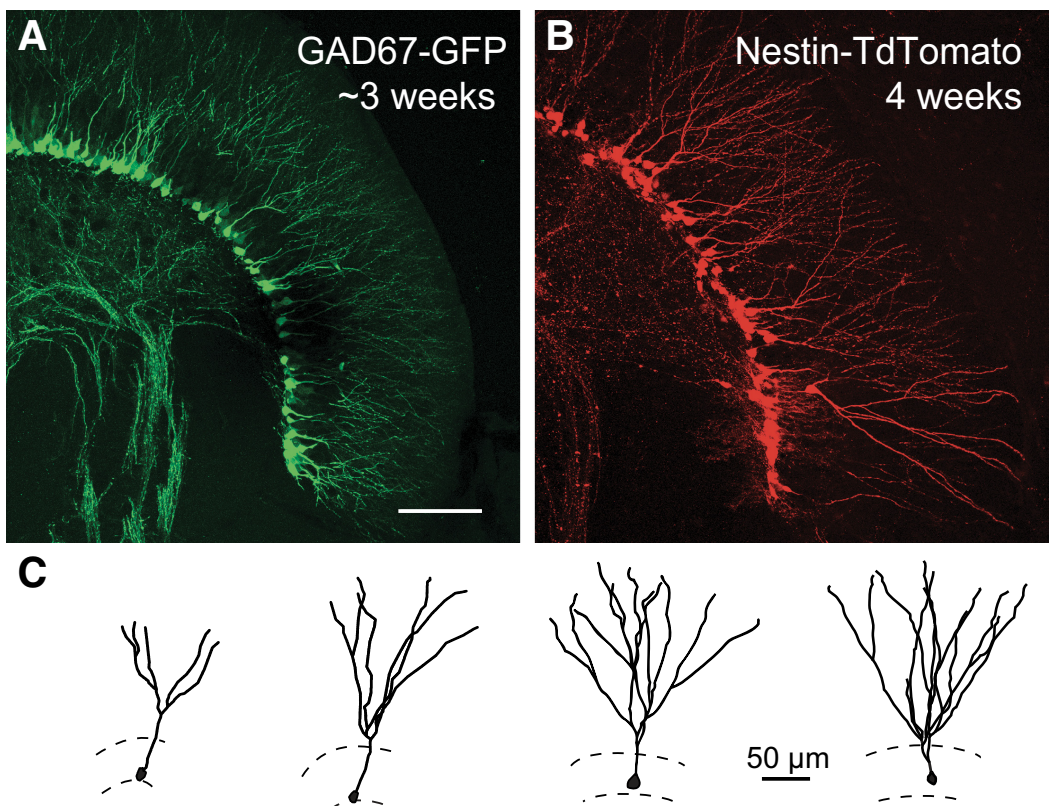

6 weeks 4 weeks

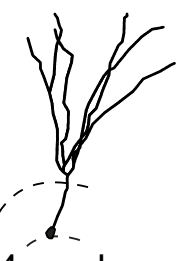

E

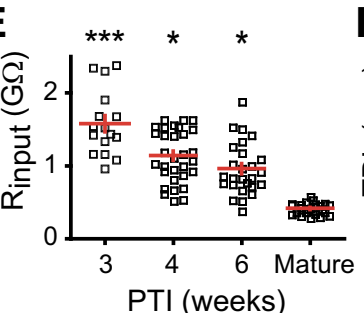

F

Mature

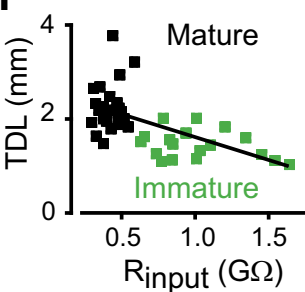

Figure 1. Identification of developing GCs in transgenic reporter mice. $\boldsymbol{A}, \boldsymbol{B}$, Confocal image of immature GCs in GAD67-GFP reporter mice ( $\boldsymbol{A})$ and TdTomato-labeled immature GCs at 4 weeks PTI in Nestin-CreER mice $(\boldsymbol{B})$. Scale bar, $100 \mu$ m. $\boldsymbol{C}$, Examples of (in $\mu \mathrm{m}$ ): $521 \pm 49,1241 \pm 50,1370 \pm 45$, and $2181 \pm 123 . n=14-24$ cells per group. All groups were different from mature , one-way ANOVA; $F_{(3,73)}=71,65 ; p<0.0001$; Tukey post-test, ${ }^{*} p<0.05$. $E$, The $R_{\text {input }}$ decreased with time. Values for $R_{\text {input }}$ ifferent from mature $\mathrm{GCS}$, one-way ANOVA; $F_{(3,93)}=44,45 ; p<0.0001$; Tukey post-test, ${ }^{* * *} p<0.05$. $\boldsymbol{F}$, The TDL and $R_{\text {input }}$ were inversely correlated, $n=43 ; R^{2}=0.36$, linear regression; $p<0.0001$. G, Example of voltage responses to current injection ( $10 \mathrm{pA}$ current steps for immature $\mathrm{GCs}$ and $20 \mathrm{pA}$ steps for mature $\mathrm{GCS})$. The holding potential was $-70 \mathrm{mV}$.

patch pipette in voltage-clamp mode. Drugs and chemicals were obtained from Sigma-Aldrich, Tocris Bioscience, or Abcam Biochemicals.

Confocal images were taken of GAD67-EGFP and Nestin-CreER ${ }^{\mathrm{T} 2}$ Td-Tomato $^{+}$immature GCs in perfusion-fixed tissue (50 $\mu \mathrm{m}$ sections) and from biocytin-filled GCs in acute slices after overnight fixation. Granule cell morphology was reconstructed from image stacks using the tracing program Neurolucida (MicroBrightField). The density of dendritic protrusions was determined from several image stacks taken with a $60 \times$ oil-immersion lens and a digital zoom of $4 \times($ step $=0.1 \mu \mathrm{m}$, kalman $=3$ ). Protrusions on three sections of dendrite in the outer and/or medial molecular layer were counted for each cell (section length, 10 $\mu \mathrm{m})$ using ImageJ (NIH). Measurements of cellular morphology included total dendrite length (TDL), number of nodes, and Sholl analysis of length and intersections. Analysis of dendritic morphology was performed using Neurolucida Explorer.

Data are expressed as the mean \pm SEM. We used two-tailed paired or unpaired $t$ tests for comparisons between two groups. We used two-way 

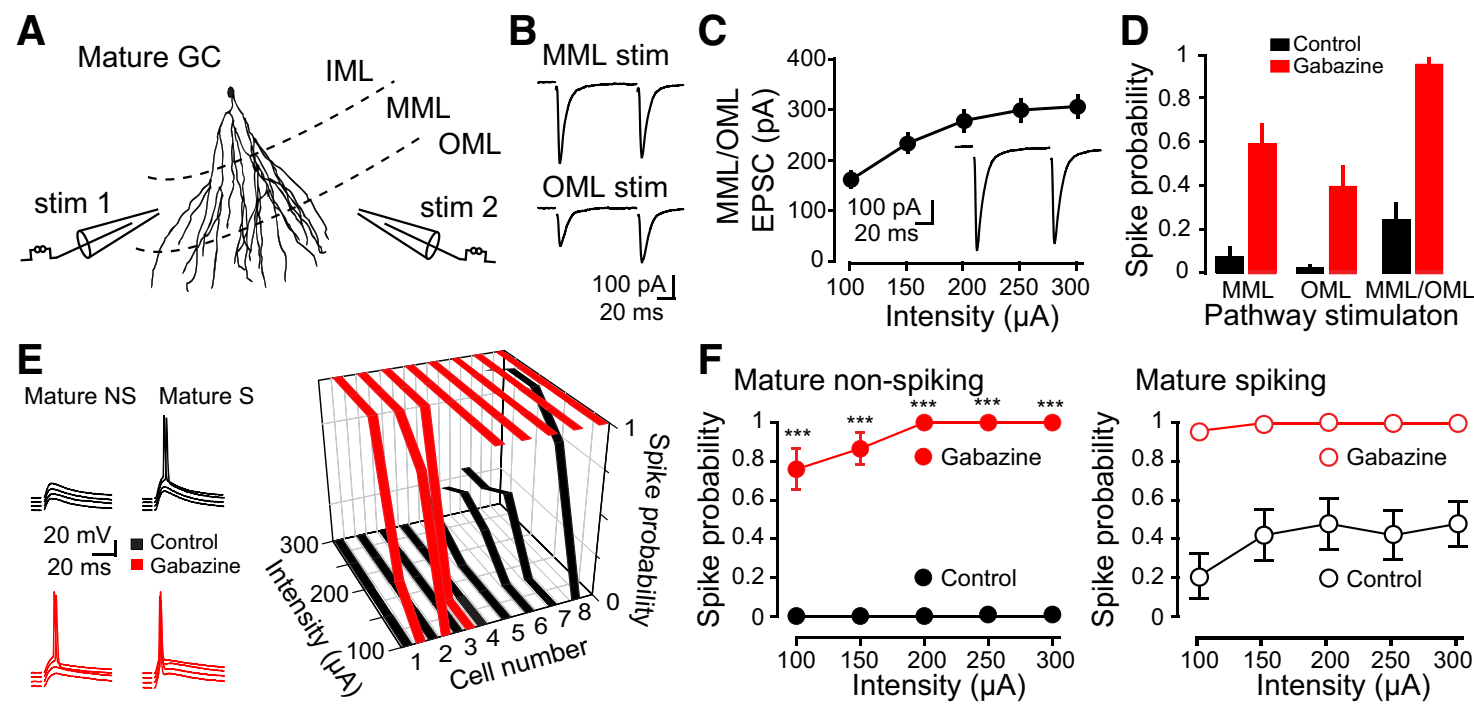

Figure 2. Spiking in mature $\mathrm{GCS}$ is suppressed by inhibition. $A$, Morphological reconstruction of a mature $\mathrm{GC}$ and schematic of the recording configuration with stimulating electrodes placed $\sim 100 \mu \mathrm{m}$ on either side of the GC. B, Examples of differential paired-pulsed ratios for EPSCs evoked by stimulation of the MML (top) and OML (bottom). Stimulus artifacts are blanked for clarity. C, The EPSC amplitude evoked by simultaneous stimulation of MML and OML at increasing stimulus intensities (100-300 $\mu \mathrm{A})$. Inset, Example of average EPSC evoked by MML/OML stimulation (same cell and stimulus intensity as in $\boldsymbol{B})$. $\boldsymbol{D}$, In gabazine (10 $\mu \mathrm{m}$; red), dual MML/OML stimulation generated spiking in all mature $\mathrm{GCs}$, unlike single-pathway stimulation ( $n=24$ cells). $\boldsymbol{E}$, Left, Example EPSPs at increasing stimulus intensities from a NS GC (left) and an SGC (right). Right, Examples of heterogeneous responses in NS (cells 1-4) and S (cells 5-8) mature GCs in control (black) and gabazine (red). Ten stimuli were tested at each intensity to calculate spiking probability. $\boldsymbol{F}$, Gabazine increased the spiking probability of NS (left; solid symbols; $n=22$ ) and $S$ (right; open symbols; $n=10)$ mature $G\left(s\right.$. Repeated-measures ANOVA: NS $\times$ gabazine: $F_{(1,28)}=662, p<0.0001 ; \operatorname{stim} \times$ NS $\times$ gabazine: $F_{(4,112)}=4.17, p=0.003 ;$ interaction: $F_{(4,112)}=4.17, p=0.003$; $S \times$ gabazine: $F_{(1,18)}=26.6, p<0.0001$; stim $\times N S \times$ gabazine: $F_{(4,72)}=4.6, p=0.002$; interaction: $F_{(4,72)}=2.9, p=0.05$. Tukey's post-test, ${ }^{* * *} p<0.001$.

repeated-measures ANOVA to compare: (1) spiking versus nonspiking (NS), gabazine versus control and GCs of different ages across multiple stimulus intensities; and (2) age of GCs across control and gabazine. For other multiple comparisons, we used two-way or one-way ANOVAs. The $F$ values were used to express the significant difference or the interaction, and post hoc analyses were made with Bonferroni's or Tukey's tests (Statistica, StatSoft; and Prism, GraphPad). $\chi^{2}$ tests were used to compare the percentage of spiking cells between groups (Prism, Graph$\mathrm{Pad})$. The level of significance was set at $p<0.05$ for the ANOVA, the post hoc comparison, and the $\chi^{2}$ test. Exponential and linear functions were used for fitting, and the goodness of the fit was estimated by calculating the $\chi^{2}$ (OriginPro). The best fit was obtained by minimizing the mean square error between the data and the curve (Levenberg-Marquardt algorithm).

\section{Results}

\section{Morphological and intrinsic maturation of GCs in transgenic reporter mice}

We made whole-cell current and voltage-clamp recordings in ventral hippocampal slices from transgenic reporter mice that allow visualization of GCs at various developmental stages. We used GAD67-GFP mice to identify GCs $\sim 3$ weeks postmitosis (Fig. 1A; Zhao et al., 2010) and nestin-CreER ${ }^{\mathrm{T} 2}$ mice crossed with R26R-TdTomato reporter mice (Ai14; The Jackson Laboratory) to identify GCs between 3 and 8 weeks post-tamoxifen-induced recombination (Lagace et al., 2007; DeCarolis et al., 2013; Fig. $1 B$ ). Cells were grouped by time post-tamoxifen injection (PTI; 3 weeks $=21-24 \mathrm{~d}$ and GAD67-GFP ${ }^{+} ; 4$ weeks $=30-36 \mathrm{~d}$ PTI; and 6 weeks $=39-52 \mathrm{~d}$ PTI) to compare with unlabeled mature GCs. We sampled GCs with somata in all depths and regions of the granule cell layer with dendrites extending into the molecular layer. There was no difference in intrinsic properties of unlabeled mature GCs between WT and transgenic reporter lines (data not shown), so results from all mature GCs recordings were combined. Occasional semilunar GCs, identified by their position near the inner molecular layer (IML), distinct dendrite structure, and low input resistance (Williams et al., 2007; Gupta et al., 2012), were excluded from analysis.

There was a time-dependent increase in dendrite complexity and total dendrite length as GCs integrated into the hippocampal circuit (Fig. 1C,D), similar to newly generated GCs identified with retroviral labeling (Espósito et al., 2005; Zhao et al., 2006). GC input resistance decreased with time (Fig. 1E) and was inversely correlated with dendrite length (Fig. $1 F$ ), and both measures did not achieve values of mature GCs even after 6 weeks (Table 1; Fig. $1 D, E$ ). Conversely, the threshold and kinetics of action potentials induced by current injections largely attained mature values at 4 weeks PTI (Fig. $1 G$; Table 1; Mongiat et al., 2009). The action potential threshold for current injections was depolarized at 3 weeks PTI, likely reflecting a lower density of voltage-gated sodium channels that also underlies the slow kinetics of action potentials (Table 1; MacDermott and Westbrook, 1986). These results show that the protracted period of GC maturation identified using retroviral labeling is also evident in transgenic reporters and that the maturation of GC spiking occurs before other measures of maturation such as input resistance and dendrite length. Variability in dendrite length and input resistance between the 4and 6-week time points likely reflects heterogeneous activitydependent maturation of individual GCs (Piatti et al., 2011), the slow rate of maturation in the ventral hippocampus (Piatti et al., 2011; Snyder et al., 2012), and the temporal resolution of the nestinCreER2 line that leads to recombination in nestin-expressing stem cells (Lagace et al., 2007). Furthermore, we did not use exercise to accelerate the rate of GC maturation, potentially contributing to delayed maturation compared with that observed in dorsal hippocampus (Mongiat et al., 2009; Piatti et al., 2011).

\section{Inhibition suppresses spiking in mature GCs}

First, we tested the role of $\mathrm{GABA}_{\mathrm{A}}$ receptor-mediated inhibition on the probability that mature GCs generate an action potential (spike probability) in response to afferent stimula- 
tion. Mature GCs were initially identified by relatively large unlabeled somata and subsequently confirmed by characteristic intrinsic properties (Table 1). Axons from layer II pyramidal cells in the medial entorhinal cortex (MEC) and lateral entorhinal cortex (LEC) innervate GCs in the DG molecular layer, with sensory information conveyed via the lateral perforant path in the outer molecular layer (OML) and locationspecific information conveyed via the medial perforant path in the middle molecular layer (MML). Since GC activity reflects the convergence of these two pathways, we stimulated each simultaneously (Fig. 2A), evoking EPSCs and EPSPs with increasing stimulus intensities. The paired-pulse ratio of MMLand OML-evoked EPSCs was $0.93 \pm 0.02$ and $1.23 \pm 0.03$, respectively (Fig. $2 B ; n=11$; unpaired $t$ test, $p<0.0001$ ) and dual-pathway-evoked EPSCs were nearly the sum of individual inputs (Fig. 2C, inset). Thus, dual-pathway stimulation reflects the integration of medial and lateral perforant path inputs. Rather than normalize for stimulus intensity across cells (Pouille et al., 2009; Marín-Burgin et al., 2012), we only assumed that increasing stimulus intensity recruits additional axons, as shown by the increase in EPSC amplitude (Fig. 2C). Unlike single-pathway stimulation, dual-pathway stimulation in the presence of the $\mathrm{GABA}_{\mathrm{A}}$ receptor antagonist gabazine (3 $\mu \mathrm{M})$ generated spiking in all GCs, indicating that excitatory input with dual stimulation was always sufficient to reach threshold ( $n=24$; Fig. 2D; measured at $300 \mu \mathrm{A})$.

We classified GCs as either nonspiking or spiking based on their behavior with inhibition intact (Fig. 2E, left). Examples of spiking probability heterogeneity are shown in Figure $2 E$, right, illustrating NS cells (cells 1-4) and S cells (cells 5-8). Gabazine dramatically increased the spiking probability in all mature GCs (Fig. 2F; $n=22 \mathrm{NS}$ cells, $n=10 \mathrm{~S}$ cells), indicating that synaptic inhibition maintains sparse GC firing with this stimulating paradigm. With inhibition intact, only 8 and $21 \%$ of mature GCs spiked at the lowest and highest stimulus intensity, respectively ( $n=95$ mature GCs). This low fraction of spiking GCs is similar to that recently reported using an in vitro imaging approach (Yu et al., 2013), yet higher than that reported in vivo during exploration of a novel environment or spatial learning tasks (Chawla et al., 2005; Kee et al., 2007; Stone et al., 2011).

\section{Intrinsic differences cannot account for heterogeneous spiking}

We tested whether intrinsic properties contributed to the heterogeneous spiking behavior but found no differences in the input resistance, the membrane time constant, or AP threshold in response to current injections between spiking and nonspiking mature GCs (Fig. $3 A, B$, Table 1). In spiking GCs, the action potential threshold in response to synaptic stimulation was significantly hyperpolarized by gabazine, suggesting that synaptic stimulation activated $\mathrm{GABA}_{\mathrm{A}}$ receptors at the axon initial segment (Rojas et al., 2011). However, in gabazine there was no difference in the action potential threshold in response to synaptic stimulation between nonspiking and spiking cells (Fig. 3B). There were also no differences in the dendrite structure or spine density in a subset of morphologically reconstructed mature GCs (Fig. 3C-F). Thus, neither intrinsic excitability nor morphology contributed to heterogeneous spiking.
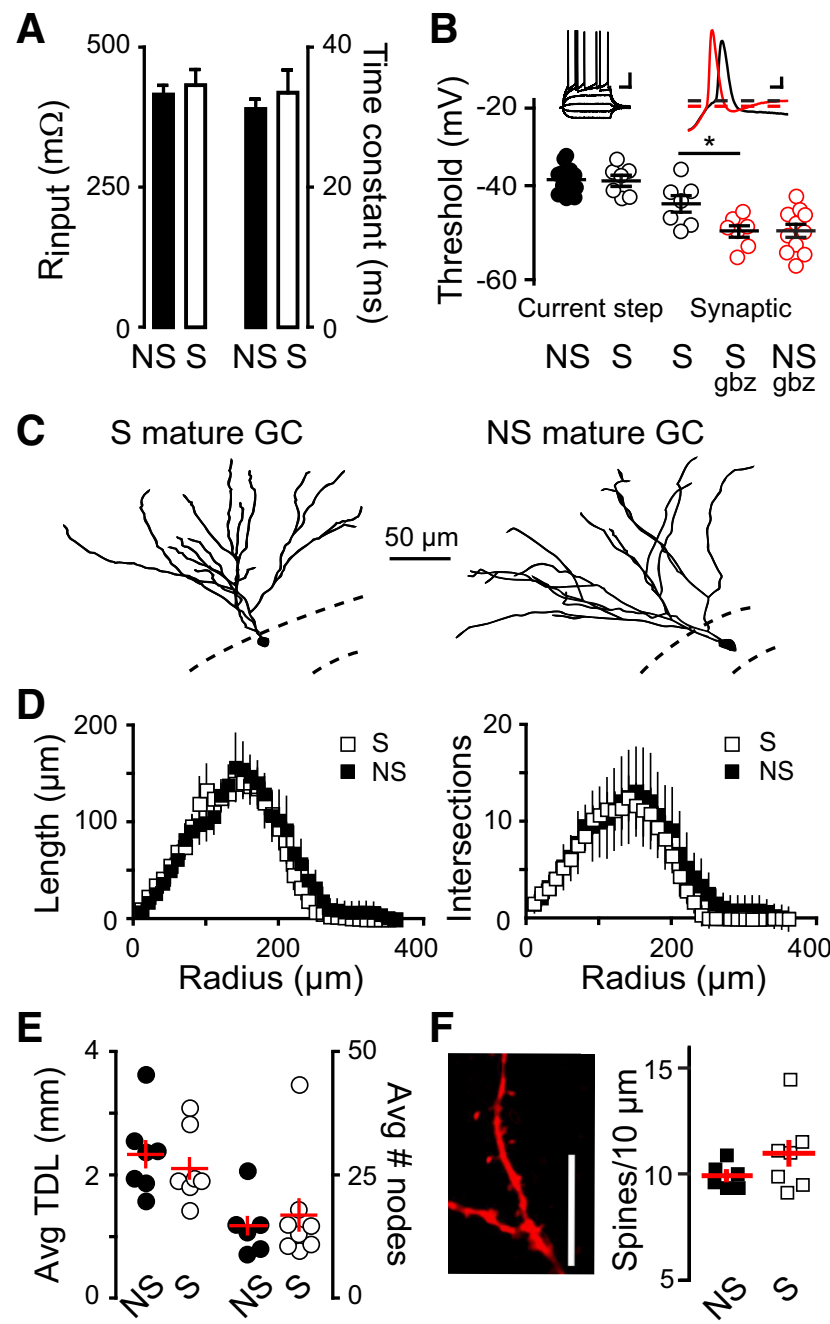

$\mathbf{F}$

Figure 3. Intrinsic differences cannot account for heterogeneous spiking of mature GCs. $A$, Nonspiking and spiking mature GCs had the same input resistance $[415 \pm 17 \mathrm{M} \Omega(n=22)$ and $432 \pm 28 \mathrm{M} \Omega(n=10)$; unpaired $t$ test, $p=0.6$ ] and membrane time constant ( $31.1 \pm 1.4$ and $33.5 \pm 3.2 \mathrm{~ms}, p=0.5)$. $\boldsymbol{B}$, Action potential thresholds in response to current injections (left) or synaptic stimulation (right). The synaptic action potential threshold was hyperpolarized by gabazine (one-way ANOVA, $p<0.0001, F_{(4,53)}=24,33$, Tukey's post-test; ${ }^{*} p<0.05, n=$ 7). The synaptic AP threshold for nonspiking and spiking GCs was not different in gabazine $[-51 \pm 1.4 \mathrm{mV}(n=7)$ and $-51.7 \pm 1.5 \mathrm{mV}(n=12)$, respectively; ANOVA with Tukey's post-test, $p>0.05$, red symbols). The AP threshold in response to current injections was the same in nonspiking and spiking GCs $(-37.5 \pm 0.7$ and $-37.6 \pm 1.4 \mathrm{mV}$; ANOVA with Tukey's post-test, $p>0.05$ ). Insets show example voltage traces following current injections (left) or synaptic stimulation in control (black) or gabazine (red). Calibration: left, $20 \mathrm{mV}$ and $100 \mathrm{~ms}$; right, $10 \mathrm{mV}$ and $2.5 \mathrm{~ms}$. Dotted lines indicate threshold. C, Morphological reconstructions. D, Sholl analysis revealed no differences in the dendrite length and number of intersections $(n=$ 9 each). Two-way repeated-measures ANOVA, $p>0.05$. $E$, The average total dendrite length and number of nodes was not different; unpaired $t$ test, $p=0.6$ for TDL, $p=0.5$ for nodes. $\boldsymbol{F}$, Left, Confocal image of spines on a mature GC. Scale bar, $10 \mu \mathrm{m}$. Right, No difference in the number of spines per $10 \mu \mathrm{m}$ length of dendrite ( $n=7$ S and 6 NS cells); unpaired $t$ test, $p=0.9$.

\section{IPSC/EPSC ratio controls EPSP amplitude and spiking probability in mature GCs}

The lack of intrinsic differences and the larger amplitude of subthreshold EPSPs in spiking GCs suggested that the balance of synaptic excitation and inhibition may dictate spiking behavior (Fig. $4 A ; n=22$ NS GCs and $n=10$ S GCs; suprathreshold EPSPs were excluded). We measured inhibitory and excitatory synaptic strength using IPSCs (near the EPSC reversal potential) and EPSCs (near the IPSC reversal potential; Fig. $4 B$, left). A plot of 

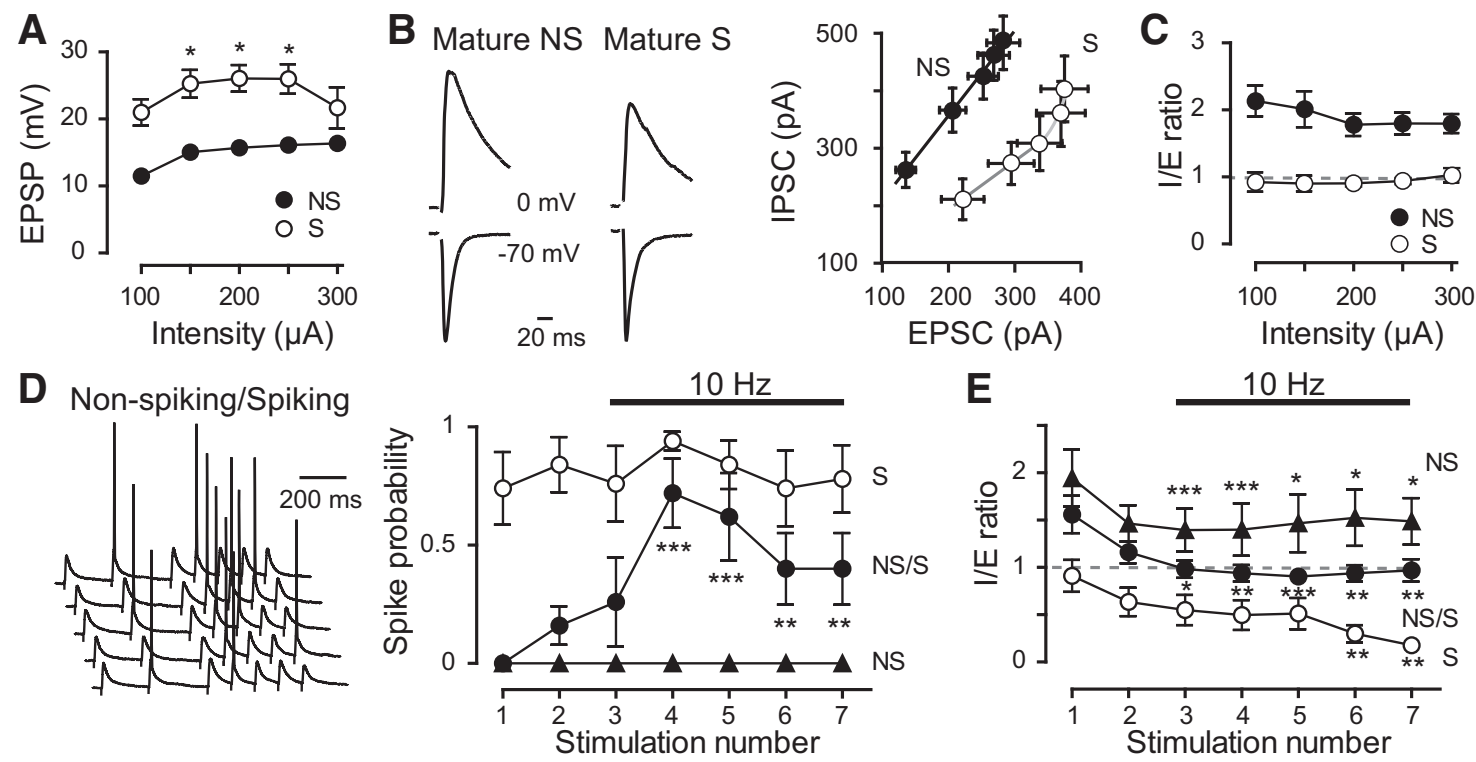

Figure 4. I/E ratio controls EPSP amplitude and spiking probability in mature GCs. $A$, EPSPs in spiking GCs (open symbols) were larger than in nonspiking GCs (solid symbols). Repeated-measures ANOVA; NS $\times S: F_{(1,30)}=40.8, p<0.0001 ;$ stim $\times N S \times S: F_{(4,120)}=49.2, p<0.0001$; Tukey's post-test, ${ }^{*} p<0.05$. B, Left, Examples of IPSCs (top) and EPSCs (bottom). Right, Amplitudes of IPSCS and EPSC $s$ were binned by stimulus intensity ( $n=22 \mathrm{NS} \mathrm{GCS}$ and $10 S \mathrm{GCS}$, repeated-measures ANOVA, $\left.F_{(1,58)}=5.7, p=0.02\right)$. Whereas NS GCS showed a linear relationship between EPSC and IPSCS (black line, $\left.R^{2}=0.98\right)$, in $S$ cells the relationship was more complex, with a linear relationship at low intensities $\left(R^{2}=0.98\right.$; dark gray) and an exponential fit at higher intensities that suggests saturation (light gray; $R^{2}=0.98$ ). C, Normalizing excitatory drive by plotting the I/E ratio revealed a robust difference between nonspiking and spiking GCs. Repeated-measures ANOVA; NS $\times S: F_{(1,30)}=18.68, p<0.001$. D, Left, Example of spiking during a $10 \mathrm{~Hz}$ stimulus train in a mature GC that did not spike to a single stimuli. Right, Spiking probability remained zero in most nonspiking $\mathrm{GCS}(n=7)$, but a subset spiked during repetitive stimulation (NS/SGCs;n=5). The spiking probability did not change during the train in the $S$ cells $(n=5)$, but increased in NS/S cells. Two-way repeated-measures ANOVA; NS $\times$ NS $/ S \times S: F_{(2,14)}=27.2, p<0.0001 ;$ stim $\times N S \times N S / S \times S: F_{(6,84)}=7.68, p<0.0001 ;$ interaction: $F_{(12,84)}=4.57, p<0.0001$. Tukey's post-test, ${ }^{* * *} p=0.0001,{ }^{* *} p=0.001$. $E$, The I/E ratio decreased during $10 \mathrm{~Hz}$ stimulation in all GCS, and the I/E ratio in NS/S GCS went to $<1$ (dotted line). Tw0-way repeated-measures ANOVA; NS $\times$ $\mathrm{NS} / \mathrm{S} \times \mathrm{S}: F_{(2,14)}=6.6, p<0.01 ; \operatorname{stim} \times \mathrm{NS} \times \mathrm{NS} / \mathrm{S} \times \mathrm{S}: F_{(6,84)}=12.65 p<0.0001$; Tukey's post hoc test, ${ }^{* * *} p<0.001,{ }^{* *} p<0.01,{ }^{*} p<0.01$.

the IPSC and EPSC amplitude at each stimulus intensity revealed a robust difference between nonspiking and spiking mature GCs (Fig. $4 B$, right). To compare inhibitory synaptic drive across different levels of excitatory drive, we expressed inhibition relative to excitation [IPSC/EPSC (I/E) ratio]. There was variability in I/E ratio that ranged from 0.22 to $6.9(n=32$ GCs, all stimulus intensities; data not shown). Nonspiking GCs had a significantly higher I/E ratio than spiking GCs (Fig. 4C), suggesting that dualpathway stimulation recruited more inhibition relative to excitation, thus preventing spiking.

To address whether the I/E ratio was causally related to spiking probability, we altered the I/E ratio using $10 \mathrm{~Hz}$ train stimulation (Ewell and Jones, 2010). Although the action potential probability of most nonspiking cells remained zero $(n=7$ of 17 cells), a subset of nonspiking cells began to fire during the train (Fig. $4 D$, NS/S cells; $n=5$ of 17 cells). The action potential probability of spiking GCs remained high throughout the train ( $n=5$ of 17 cells). The I/E ratio in all mature GCs was reduced during the $10 \mathrm{~Hz}$ stimulation, demonstrating a relative reduction of inhibition (Fig. $4 E$ ). The I/E ratio of the nonspiking cells that spiked during the train (NS/S cells) fell below 1, whereas the nonspiking cells that did not spike during the train (NS cells) maintained an I/E ratio of $>1$ (Fig. $4 C$ ). Together, these results suggest that the $\mathrm{I} / \mathrm{E}$ ratio is a key determinant of spiking probability and that mature GCs spike when the I/E ratio $<1$.

\section{Minimal innervation limits spiking at 3 weeks PTI}

To examine synaptic activation in developing GCs, we first targeted immature GCs with dendrites projecting through the ML in GAD67-GFP mice ( $~ 3$ weeks old; Zhao et al., 2010$)$ and GCs labeled in nestin-CreER ${ }^{\mathrm{T} 2} / \mathrm{Td}$-tomato mice at $21-24 \mathrm{~d}$ PTI (Lagace et al., 2007). By this stage, all GCs fired one or a few spikes with immature properties in response to current injection (3 weeks; Fig. 1G; Table 1; Mongiat et al., 2009). Although MML/ OML stimulation evoked EPSPs in all cells, it never evoked spiking even when inhibition was blocked by gabazine (Fig. 5A). $\mathrm{GABA}_{\mathrm{A}}$ receptor activation initially depolarizes newborn GCs due to the high intracellular $\left[\mathrm{Cl}^{-}\right]$, and the $\mathrm{Cl}^{-}$reversal potential shifts to mature values between 2 and 4 weeks postmitosis (Ge et al., 2006). However, the low intracellular $\left[\mathrm{Cl}^{-}\right]$in our recordings did not account for the lack of spiking, since GAD67-GFP GCs also did not spike when we used a higher $\left[\mathrm{Cl}^{-}\right]$intracellular solution $(23 \mathrm{mM})$. As expected, the effect of gabazine on the EPSP depended on the intracellular $\left[\mathrm{Cl}^{-}\right]$, with gabazine enhancing EPSPs recorded with low intracellular $\left[\mathrm{Cl}^{-}\right]$and reducing EPSPs recorded with high intracellular $\left[\mathrm{Cl}^{-}\right]$(Fig. $5 B$ ). Since depolarization arising from either glutamate receptors or GABA receptors was insufficient to generate spiking with dual MML/OML stimulation, we conclude that high input resistance does not dictate high spiking probability. Despite the high I/E ratio (see below), the lack of spiking in gabazine indicated that insufficient excitatory drive rather than functional inhibition prevented spiking in 3 week PTI GCs.

\section{Enhanced spiking at 4 weeks PTI in response to ML stimulation}

To determine whether the I/E ratio correlates with spiking probability at later stages of GC maturation, we next examined the spiking probability and synaptic properties of immature GCs in nestin-CreER ${ }^{\mathrm{T} 2} / \mathrm{Td}$-tomato reporter mice at 4 and 6 weeks 
PTI. By 4 weeks, labeled GCs fired trains of APs in response to current injections with largely mature characteristics (Table 1). Similar to mature GCs, 4 week PTI GCs displayed heterogeneity in response to MML/OML synaptic stimulation, with some cells that never spiked (NS cells; $n=$ 7) and some cells that increased spiking probability with increasing stimulation intensity ( $\mathrm{S}$ cells; $n=8$; Fig. $5 C$ ). In both cases, the spiking probability was increased by gabazine (Fig. $5 C$, red symbols), illustrating that inhibition limits AP generation. An additional cell did not spike in gabazine, likely due to insufficient excitatory drive evident by the small EPSC (data not shown). In contrast to mature GCs, the spiking probability of nonspiking 4 week PTI GCs remained $<1$ when inhibition was blocked, suggesting that low excitatory drive was a limiting factor in spiking. Furthermore, a plot of the number of spikes versus current amplitude for somatic current injections revealed that spiking 4 week PTI GCs generated one to two more spikes compared with nonspiking cells (data not shown), suggesting that intrinsic properties other than input resistance promotes spiking (Schmidt-Hieber et al., 2004).

Six week PTI GCs likewise displayed heterogeneous spiking in response to MML/OML stimulation and gabazine robustly increased the spiking probability of both nonspiking and spiking cells (Fig. 5D). All 6 week PTI GCs fired APs in the presence of gabazine and spiking probability approached 1 at the majority of stimulus intensities when inhibition was blocked. Thus, similar to mature GCs, excitation did not limit spiking at this stage. Interestingly, synaptic inhibition not only increased EPSPs (data not shown), but also hyperpolarized the threshold for synaptic-induced spiking in both 4 and 6 week PTI GCs $[-45 \pm 4$ to $-55 \pm 2 \mathrm{mV}$ $(n=7)$ and $-42 \pm 2$ to $-49 \pm 1.6 \mathrm{mV}$ $(n=4)$, respectively; paired $t$ tests, $p<$ $0.05]$, suggesting that $\mathrm{GABA}_{\mathrm{A}}$ receptors at the axon initial segment contribute to the action potential threshold (Rojas et al., 2011).

In agreement with Marín-Burgin et al. (2012), the percentage of GCs that spiked in response to MML/OML stimulation $\left(P_{\text {spiking }}=\right.$ number of spiking cells/total number of recorded cells $X$

$100)$ differed across time, with a significant increase in $P_{\text {spiking }}$ for 4 week PTI GCs compared with mature GCs at both the lowest and highest stimulus intensities ( $\chi^{2}$ test, $p<0.01$; Fig. $5 E$ ). Comparing the amplitude of EPSCs in spiking GCs also showed that 4 week PTI GCs could spike in response to less excitatory drive 0.032 .
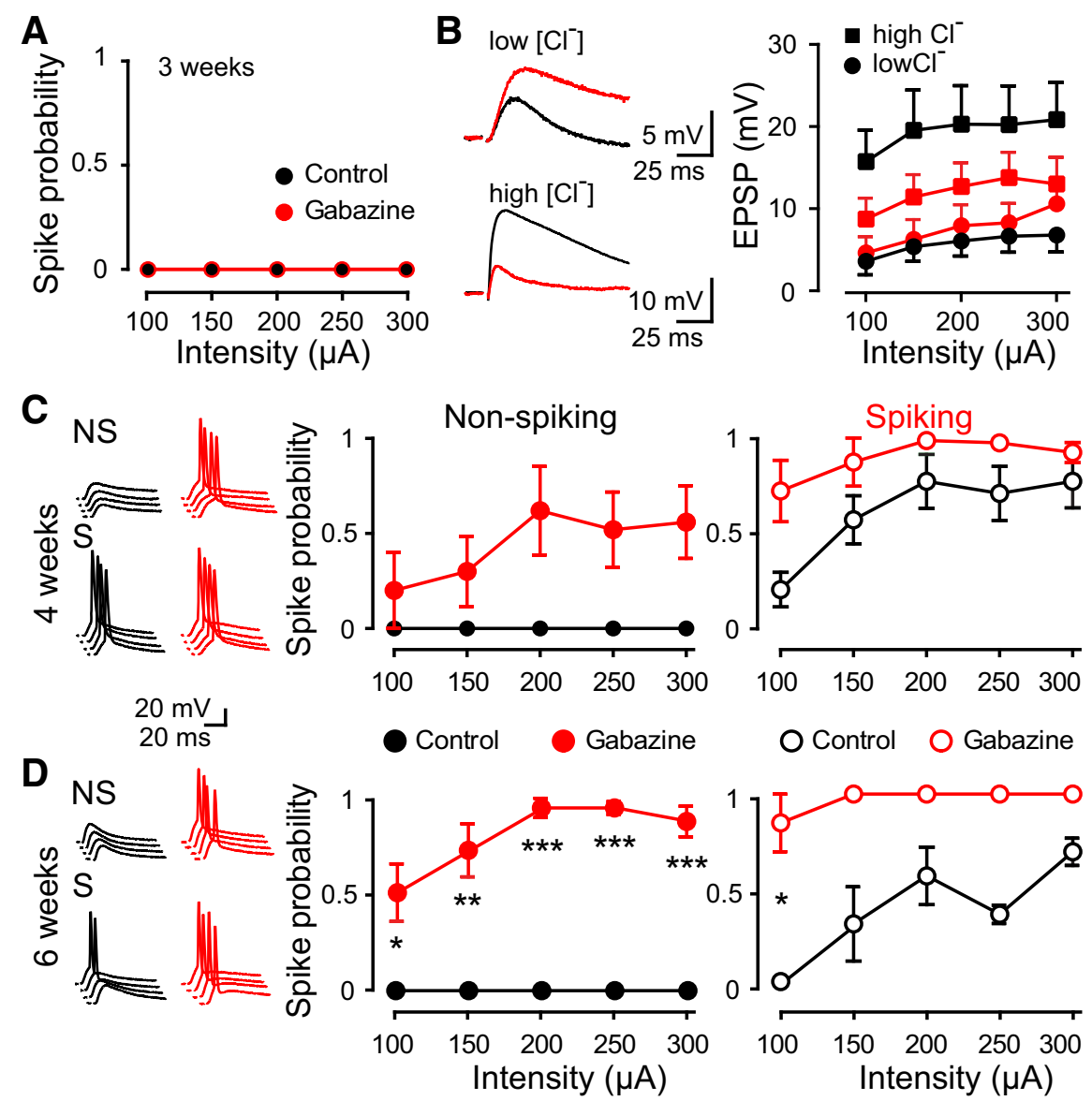

O Control O Gabazine
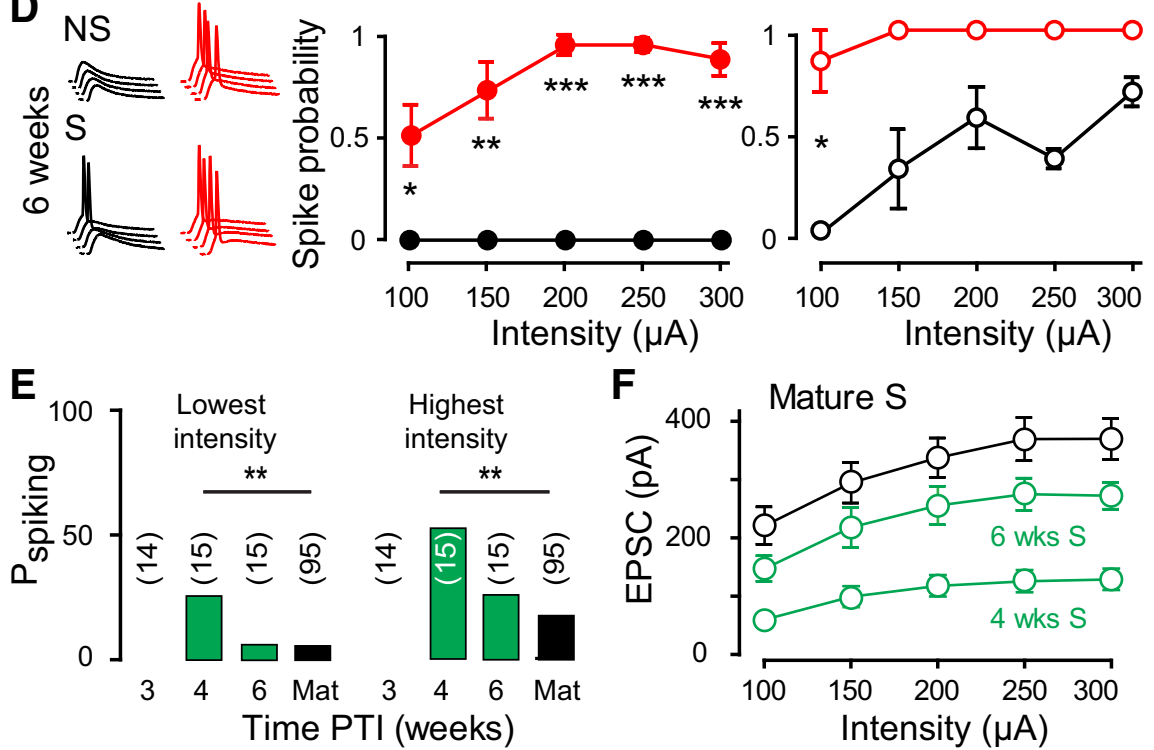

Figure 5. Enhanced spiking in GCS at 4 weeks PTI. $\boldsymbol{A}$, Three-week-old GCs failed to spike in response to dual stimulation of MML/OML even in the presence of gabazine ( $n=14$ GAD67-GFP cells). $\boldsymbol{B}$, EPSPs recorded with low (top traces, $n=8$ ) and high (bottom traces, $n=6$ ) intracellular [ $\left.\mathrm{Cl}^{-}\right]$were differentially affected by gabazine. C, Left, Examples of EPSPs evoked by MML/OML stimulation in immature GCs at 4 weeks PTI in the absence or presence of gabazine. GCs either failed to spike (NS) or increased their spiking probability (S). Calibration: $20 \mathrm{mV}, 20 \mathrm{~ms}$. Gabazine increased the spiking probability of both NS and S immature GCs. Repeated-measures ANOVA; NS $\times$ gabazine: $F_{(1,8)}=6.66, p=0.032$; and $S \times$ gabazine: $F_{(1,14)}=4.63, p=0.048$; stim $\times S \times$ gabazine: $F_{(4.56)}=12.38, p<0.0001$. D, Left, examples of EPSPs in GCs at 6 weeks PTI. Calibration: $20 \mathrm{mV}, 20 \mathrm{~ms}$. Repeatedmeasures ANOVA; NS $\times$ gabazine: $F_{(1,18)}=169.2, p<0.0001$; stim $\times S \times$ gabazine: $F_{(4,72)}=4.33, p=0.003$; interaction: $F_{(4,72)}=4.33, p=0.003 ; S \times$ gabazine: $F_{(1,6)}=37.3, p=0.0009 ;$ stim $\times S \times$ gabazine: $F_{(4,24)}=8.56, p=$ 0.0002 ; interaction: $F_{(4,24)}=3.72, p=0.02$; Tukey's post-test, ${ }^{*} p<0.05,{ }^{* *} p<0.01,{ }^{* * *} p<0.001$. $\boldsymbol{E}$, The percentage of spiking cells differed across $\mathrm{GC}$ age. The total number of cells recorded is in parenthesis. $\chi^{2}$ test, ${ }^{* *} p=0.008 . F$, EPSCs were smaller in spiking immature $\mathrm{GCs}$ compared with spiking mature $\mathrm{GCs} . n=12$ immature $\mathrm{GCs}$ and 10 mature $\mathrm{GCs}$. Repeated-measures ANOVA; mature (Mat) $\times 4$ weeks $\times 6$ weeks): $F_{(2,19)}=17.68, p=0.0005$; $\operatorname{stim} \times$ Mat $\times 4$ weeks $\times$ 6 weeks: $F_{(4,76)}=54.61, p<0.0001$; interaction: $F_{(8,76)}=3.6, p=0.001$; Mat $\times 4$ weeks: $F_{(1,64)}=32.36, p<0.0001$; 4 weeks $\times 6$ weeks: $F_{(1,40)}=27.19, p=0.0004$; Tukey's post-test: Mat $\times 4$ weeks, $p=0.0002 ; 4$ weeks $\times 6$ weeks, $p=$

(Mongiat et al., 2009; Li et al., 2012; Fig. 5F). These results confirm the enhanced excitability of 4-week-old GCs in response to ML stimulation (Marín-Burgin et al., 2012) and reveal that the time window for enhanced responsiveness is brief since it was not evident at 6 weeks PTI. 

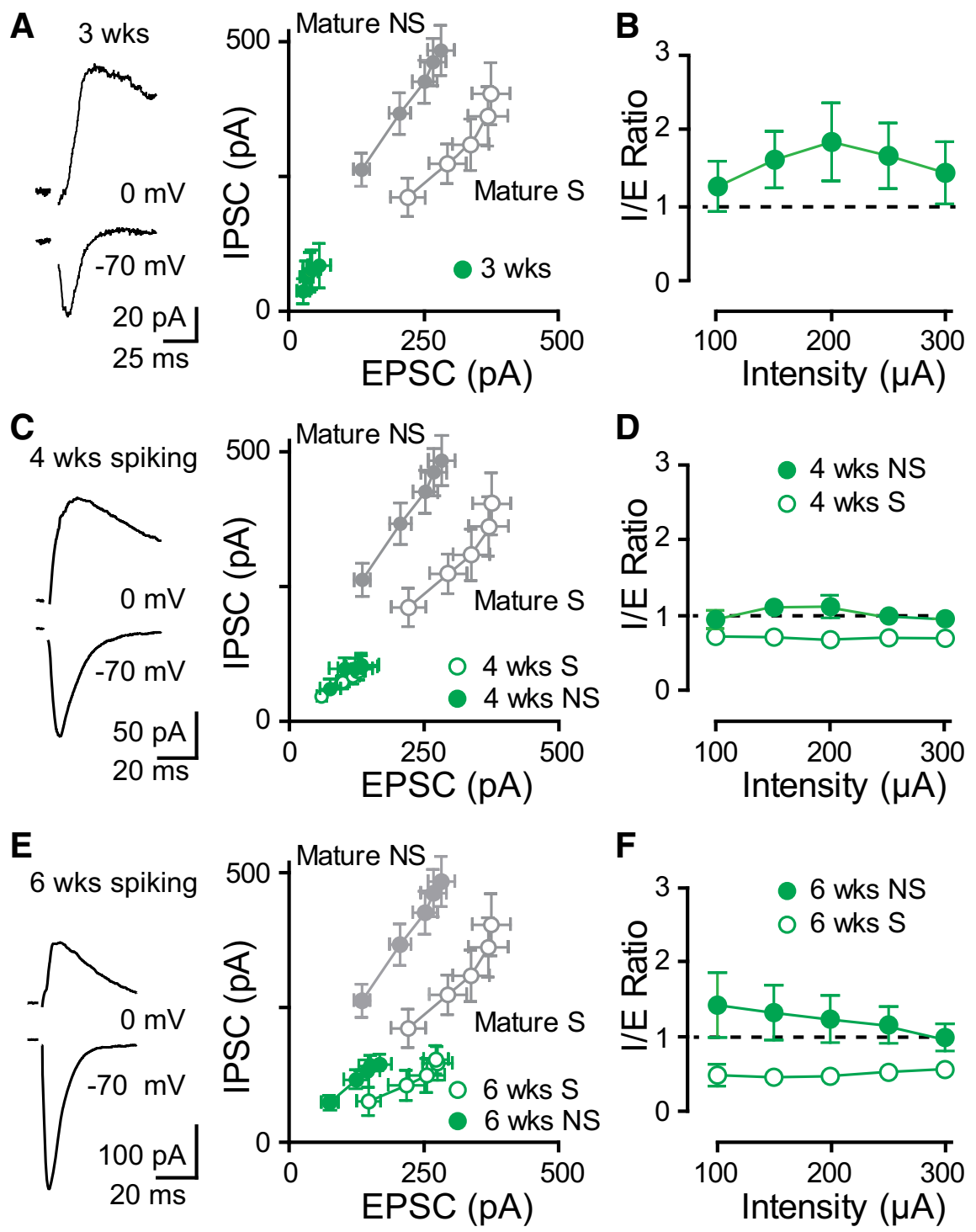

Figure 6. Maturation of excitatory and inhibitory innervation. $A, C, E$, Left, Examples of EPSCS and IPSCS at the indicated times. Right, Plots of IPSC versus EPSC amplitude from immature GCS (green symbols). Data from mature GCs are replotted for comparison (gray symbols; Fig. 5B). IPSCs and EPSCs are binned by stimulus intensity. Unlike mature GCS, there were no differences between synaptic currents in spiking and nonspiking immature $G(S . B, D, F$, Normalized I/E ratios across all stimulus intensities for each age. The I/E ratio at each stimulus intensity was calculated in individual cells and then averaged. None of the 3-week-old GCs spiked. The I/E ratio was different between NS and S GCs at 4 weeks PTI ( $n=7 \mathrm{NS}$ and $8 \mathrm{~S}$ cells; two-way repeated-measures ANOVA ( $\mathrm{N} \times \mathrm{NS}$ : $\left.F_{(1,13)}=6.42, p=0.024\right)$ but was not different between NS and S GCs at 6 weeks PTI ( $n=11$ NS and 4 S cells; $S \times$ NS: $p=0.18$ ).

\section{Delayed development of synaptic inhibition}

With sufficient excitatory drive, the higher spiking probability of immature GCs has been attributable not only to their high $\mathrm{R}_{\text {input, }}$ but also to relatively slow IPSCs that result in a high ratio of excitation to inhibition at the time of spiking (Marín-Burgin et al., 2012). We likewise found that the rise time of IPSCs differed across time ( $3.3 \pm 0.3 \mathrm{~ms}, n=32$ mature GCs; $6.5 \pm 0.5 \mathrm{~ms}, n=$ 154 week PTI GCs; $5.6 \pm 0.7$ ms, $n=156$ week PTI GCs; one-way ANOVA with Tukey post-test, $p<0.001$ ), but the rise times were not different between spiking and nonspiking cells at each time point (Table 1). Since the I/E ratio was a key determinant of spiking in mature GCs, we measured synaptic currents and the I/E ratio in immature GCs after testing their spiking probability. In voltage-clamp recordings with low intracellular $\left[\mathrm{Cl}^{-}\right.$], 3-week-old GCs displayed small EPSCs and IPSCs in response to MML/OML stimulation, which are plotted for compar- ison with the synaptic currents in mature spiking and nonspiking GCs (Fig. $6 A ; n=$ 8). Normalizing inhibition to excitatory drive revealed that the $\mathrm{I} / \mathrm{E}$ ratio was variable and high ( $>1$; Fig. $6 B$, all NS cells), consistent with the sequential formation of GABAergic synapses before glutamatergic synapses (Espósito et al., 2005; Overstreet Wadiche et al., 2005; Ge et al., 2006). However, the small EPSC amplitude supports the idea that insufficient excitatory drive, rather than inhibition (Fig. $5 A)$, limits spiking at this early developmental stage.

Plotting the amplitude of synaptic currents at 4 and 6 weeks PTI illustrated that the full development of inhibitory and excitatory innervation requires $>6$ weeks, since IPSCs and EPSCs were smaller than in mature GCs (Fig. 6A,C,E, compare right panels; Table 1 ). The robust role of the $\mathrm{I} / \mathrm{E}$ ratio in suppressing spiking likewise appeared to develop gradually since the separation of synaptic responses in nonspiking and spiking cells was not evident until 6 weeks (Fig. 6A, C,E, compare separation of $S$ and NS cells). Similar to mature GCs, the I/E ratio at 4 and 6 weeks PTI did not differ across stimulus intensity, and the ratio of spiking cells was $<1$ (Fig. 6D,F, open symbols). Despite the apparent difference in the $\mathrm{I} / \mathrm{E}$ ratio between spiking and nonspiking GCs at 6 weeks PTI, there was no statistical difference between groups, presumably due to the large variability in the I/E ratio of nonspiking GCs and the low number of spiking cells (Fig. $6 F$ ). Together, these results suggest that GCs at all developmental stages spike when the I/E ratio is $<1$ as long as excitatory drive is sufficient to achieve threshold. In the absence of sufficient excitatory drive (immature GCs with low spiking probability even in gabazine), the low I/E ratio does not predict spiking. Between 4 and 6 weeks of maturation, there is increased synaptic innervation that leads to heterogeneity in $\mathrm{I} / \mathrm{E}$ ratio and stronger suppression of spiking by inhibition.

\section{Inhibition suppresses spiking in cell-attached recordings}

It is well established that GC spiking is suppressed by strong synaptic inhibition that relies primarily on shunting (Staley and Mody, 1992; Coulter and Carlson, 2007; Chiang et al., 2012; Sauer et al., 2012; Yu et al., 2013), yet the robust role of inhibition in our experiments could be overestimated by the low intracellular concentration of $\mathrm{Cl}^{-}$in our whole-cell recordings. We thus examined spiking probability using noninvasive cell-attached recordings and the same stimulation paradigm described in Figure 2. Consistent with the whole-cell results, mature GCs displayed either no spiking or an increase in spiking probability in response to increasing intensity MML/OML stimulation, and subsequent addition of gabazine increased spiking in all cases (Fig. $7 A, D ; n=$ 


\begin{tabular}{|c|c|c|c|c|c|c|c|}
\hline & \multicolumn{2}{|l|}{ Mature } & \multicolumn{5}{|l|}{ Immature } \\
\hline & \multirow[b]{2}{*}{ NS $(n=22)$} & \multirow[b]{2}{*}{$S(n=10)$} & \multirow{2}{*}{$\frac{3 \text { weeks }}{\text { NS }(n=8)}$} & \multicolumn{2}{|l|}{4 weeks } & \multicolumn{2}{|l|}{6 weeks } \\
\hline & & & & $\operatorname{NS}(n=7)$ & $S(n=8)$ & $\operatorname{NS}(n=11)$ & $S(n=4)$ \\
\hline EPSP amplitude (mV) & $16.8 \pm 0.4^{*}$ & $25.6 \pm 1.6$ & $6.1 \pm 1.8$ & $18.3 \pm 2.2$ & $21.4 \pm 1.8$ & $20.6 \pm 0.7^{*}$ & $25.7 \pm 1.6$ \\
\hline EPSP rise (ms) & $2.6 \pm 0.1$ & $2.4 \pm 0.2$ & $5.6 \pm 1.8$ & $4.0 \pm 0.3$ & $4.2 \pm 0.7$ & $4.3 \pm 0.4$ & $3.8 \pm 0.4$ \\
\hline AP peak (mV) & $120 \pm 2$ & $116 \pm 4$ & $80 \pm 4.2^{* *}$ & $104 \pm 5^{* *}$ & $96 \pm 5^{* *}$ & $114 \pm 2$ & $116 \pm 8$ \\
\hline EPSC amplitude (pA) & $281 \pm 25^{*}$ & $376 \pm 32$ & $53.6 \pm 21$ & $130 \pm 31$ & $136 \pm 17$ & $169 \pm 22^{*}$ & $272 \pm 23$ \\
\hline EPSC rise (ms) & $1.8 \pm 0.1$ & $1.7 \pm 0.1$ & $1.0 \pm 0.5$ & $2.2 \pm 0.5$ & $2.6 \pm 0.4$ & $1.9 \pm 0.2$ & $2.0 \pm 0.2$ \\
\hline IPSC amplitude (pA) & $485 \pm 47$ & $393 \pm 57$ & $85 \pm 41$ & $110 \pm 16$ & $115 \pm 29$ & $144 \pm 19$ & $153 \pm 26$ \\
\hline IPSC rise (ms) & $3.0 \pm 0.3$ & $3.9 \pm 0.7$ & $2.8 \pm 0.7$ & $5.9 \pm 0.7^{* *}$ & $6.9 \pm 0.5^{* *}$ & $6.1 \pm 0.8^{* *}$ & $4.3 \pm 0.9$ \\
\hline
\end{tabular}

All values represent the mean \pm SEM measured at the highest stimulus intensity.

*Unpaired $t$ test $p<0.05$ for comparison between $S$ and NS in the same time group. ${ }^{* *}$ ANOVA with Tukey's test, $p<0.05$ for comparison with corresponding $S$ and NS mature GC values. Other statistical comparisons are noted in the Results.

13). In gabazine, all mature GCs spiked with a probability of 1 at stimulus intensities greater than $100 \mu \mathrm{A}$. Thus, similar to wholecell recordings, excitatory drive did not limit spiking of mature GCs, but spiking was strongly suppressed by inhibition.

Cell-attached recordings from 4 week PTI GCs also revealed both nonspiking and spiking responses in the same stimulus paradigm, and gabazine increased $P_{\text {spiking }}$ as well as the average spiking probability (Figs. $7 B, D, 9 D ; n=13$ ). However, 5 of 13 immature GCs failed to spike even in gabazine (Fig. $7 C$ ), resulting in a lower $P_{\text {spiking }}$ compared with mature GCs $(61.5 \%$ compared with $100 \%$; Fig. $7 D$ ). Thus, the enhanced excitability of 4 week PTI GCs was masked by lower excitatory drive that presumably resulted from less innervation, since all 4 week PTI GCs were capable of spiking (Fig. 1; Table 1). Together, these results further demonstrate that the high intrinsic excitability of immature GCs is limited by both functional inhibition and excitatory drive.

\section{Reduced I/E ratio of immature GCs in response to EC stimulation}

Our results suggest that the relative importance of synaptic inhibition in suppressing spiking increases across GC development as the I/E ratio increases. However, high I/E ratios and robust effects of gabazine could result from direct stimulation of interneurons in addition to perforant path-mediated feedforward inhibition. In fact, we were unable to isolate pure feedforward IPSCs (assayed by sensitivity of IPSCs to NBQX/AP-5; data not shown). To avoid recruiting local inhibition, we also examined I/E ratios following stimulation in the EC, maintained in our horizontal sections (Boulton et al., 1992).

Focal stimulation in the MEC generated EPSCs in mature GCs with paired-pulse depression, whereas LEC stimulation evoked EPSCs with paired-pulse facilitation (Fig. $8 A, B ; 0.82 \pm 0.03$ and $1.22 \pm 0.05$, respectively, $n=14$, unpaired $t$ test, $p<0.0001$ ). Dual-pathway stimulation evoked EPSCs that were nearly the sum of each input (Fig. $8 C$, dotted line), suggesting that largely independent pathways were recruited. The short latency of EPSCs was consistent with a monosynaptic connection (5.0 \pm 0.4 ms, $n=24)$. Importantly, both EPSCs and IPSCs evoked by dual MEC/LEC stimulation were completely blocked by NBQX and APV (Fig. 8D, left), assuring that no monosynaptic inhibition was recruited. The average I/E ratio in response to MEC/LEC stimulation was variable but similar to the I/E ratio following MML/ OML stimulation [Fig. $8 D$, right; $1.31 \pm 0.15(n=24)$ and $1.55 \pm$ $0.12(n=32)$, respectively; unpaired $t$ test, $p=0.2]$. In immature GCs at 4 weeks PTI, MEC/LEC stimulation likewise generated
EPSCs and feedforward IPSCs blocked by NBQX/AP- 5 with the same I/E ratio as MML/OML stimulation [Fig. $8 E ; 0.72 \pm 0.16$ $(n=9)$ and $0.80 \pm 0.08(n=30)$, respectively; unpaired $t$ test, $p=0.5]$. Furthermore, the I/E ratio evoked by MEC/LEC stimulation was lower in immature GCs compared with mature GCs $[0.72 \pm 0.16(n=9)$ and $1.31 \pm 0.15(n=24)$, respectively; unpaired $t$ test, $p<0.05$; NS and S cells combined]. Together, these results confirm that activation of pure feedforward inhibitory circuits generates a range of I/E ratios and that the average $\mathrm{I} / \mathrm{E}$ ratio at 4 weeks PTI is lower than that in mature GCs.

\section{Distinct determinants of spiking across development}

In summary, examining IPSCs, EPSCs, and spiking probabilities revealed new features about the synaptic integration of newly generated GCs. First, there is a gradual increase of both excitatory and inhibitory synaptic input that does not achieve mature levels until after 6 weeks (measured by the EPSC and IPSC amplitudes; Fig. 9A). A time-dependent increase in excitatory innervation is consistent with prior retroviral labeling studies that track the integration of adult-generated cells (Espósito et al., 2005; Ge et al., 2006; Mongiat et al., 2009). Second, the relatively delayed establishment of inhibitory innervation appears to account for the increase in the I/E ratio during maturation (Fig. 9B). Third, synaptic inhibition suppresses GC spiking and the degree of suppression increases with maturation of the I/E ratio. The role of inhibition in spiking was evident in both whole-cell (Fig. 5) and cell-attached recordings (Fig. 9C), suggesting that inhibition relies on shunting rather than hyperpolarization (Chiang et al., 2012). Finally, we show that many GCs at every developmental stage do not spike and that the reason they do not spike differs across developmental stage. This is illustrated by plotting the percentage of nonspiking cells $\left(P_{\text {nonspiking }}\right)$ from cell-attached recordings (Fig. 9D). With inhibition intact, the majority of mature and immature GCs are nonspiking, consistent with sparse population activity. When inhibition is removed, all mature GCs spike, whereas a large fraction of immature GCs remain silent due to an insufficient excitatory drive. Thus, distinct determinants maintain sparse activation of immature and mature GCs.

\section{Discussion}

Our results suggest that the protracted period of synaptic innervation of newly generated GCs yields distinct contributions of excitation and inhibition to perforant path-evoked spiking. Functional synaptic inhibition limited spiking by 4 weeks PTI, but the restric- 
A Non-spiking mature Control Gabazine
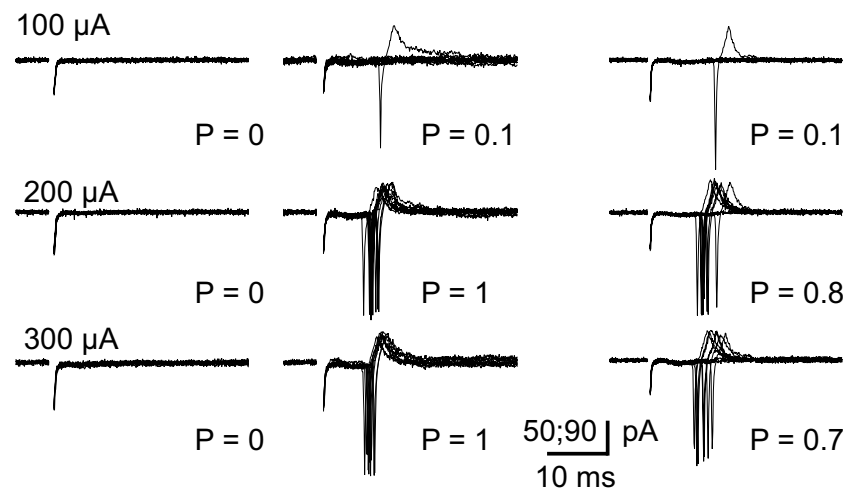

Spiking mature Control
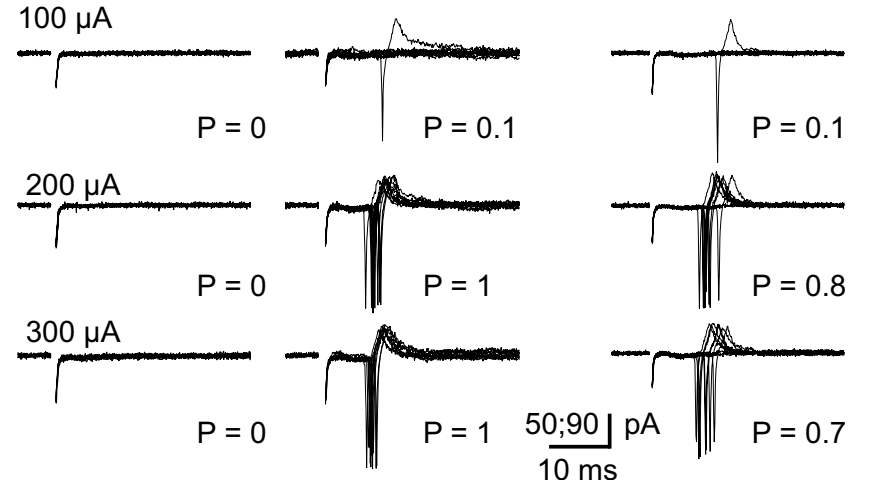

B Non-spiking 4 week-PTI Control

Gabazine
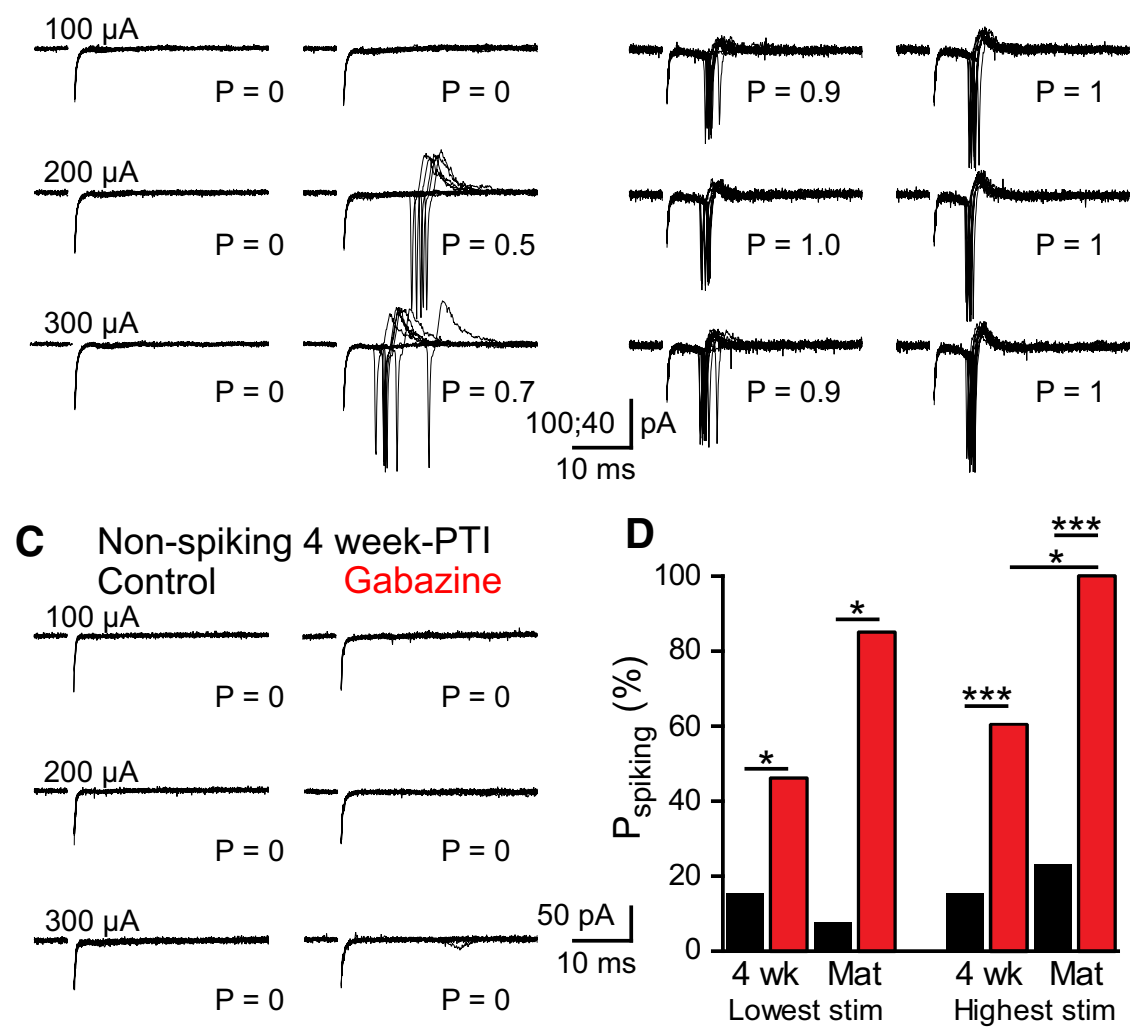

Figure 7. Inhibition suppresses spiking in cell-attached recordings. $\boldsymbol{A}, \boldsymbol{B}$, Example cell-attached recordings from nonspiking and spiking mature $(\boldsymbol{A})$ and 4 week PTI GCS $(\boldsymbol{B})$. Increasing intensity MML/0ML stimulation (stim) is indicated on the left. Ten traces overlaid. $C$, All mature GCs spiked with high probability in gabazine, but 5 of 13 cells at 4 weeks PTI did not spike in gabazine. Stimulus artifacts are truncated. $\boldsymbol{D}$, The $P_{\text {spiking }}$ values at the lowest and highest stimulus intensity. Gabazine increased $P_{\text {spiking }}$ (red bars) in both mature and 4 week PTI GCs. The total number of cells recorded is in parenthesis. $\chi^{2}$ test, ${ }^{*} p<0.05,{ }^{* *} p<0.0001$.

tion was less robust due to the low I/E ratio, which did not achieve mature values even 6 weeks PTI. The role of excitatory drive was evident when inhibition was blocked, revealing that reduced excitatory innervation was a limiting factor at early stages of maturation despite the higher input resistance. We thus propose that reduced excitatory drive combined with functional synaptic inhibition temper the intrinsic excitability of immature GCs, potentially maintaining the sparse activation observed in vivo.

Our results provide the first characterization of intrinsic and synaptic maturation of GCs using a Nestin-CreER transgenic system (Lagace et al., 2007; DeCarolis et al., 2013). Although the
Gabazine

sequence of GC maturation is consistent with prior retroviral labeling studies, we report generally higher measures of input resistance at 4 and 6 weeks that likely stem from both technical and biological sources. First, persistent neuronal production from $\mathrm{Nestin}^{+}$stem cells produces a spectrum of cell ages at time points following tamoxifen administration. However, recording from labeled cells with dendrites that project through the molecular layer selects for the most functionally mature cells at each time interval, and at 4 weeks PTI, immature GCs displayed largely mature action potential properties, similar to prior retroviral labeling studies (Espósito et al., 2005; Mongiat et al., 2009). Second, we recorded from immature GCs in the ventral hippocampus taken from mice maintained in standard housing, conditions that are associated with slower maturation compared with dorsal hippocampus (Piatti et al., 2011; Snyder et al., 2012). Importantly, our conclusion about the changing role of excitation and inhibition in GC spiking does not depend on precise cell age but rather the functional maturation of GCs that displays region- and activity-dependent heterogeneity.

For analysis of our stimulation paradigm, we classified GCs as spiking or nonspiking depending on their behavior toward a single stimulus with inhibition intact. The dichotomy of spiking behavior (and I/E ratios) could result from authentic anatomical heterogeneity of innervation between GCs or simply from heterogeneity in the particular inputs that are stimulated, such that nonspiking GCs would spike when the stimulating electrodes are moved to a new location to activate distinct afferents. Since our stimulus paradigm presumably activates only a fraction of inputs to each GC, we cannot differentiate between these possibilities based on the distribution of the I/E ratios that we measured. However, changing the stimulus frequency was sufficient to alter the I/E ratio and spiking behavior of some mature GCs, indicating that a component of the ratio depends on stimulus parameters. Further studies are required to determine whether the heterogeneity of the I/E ratios that we observed reflects cell-specific heterogeneity rather than variability in the recruitment of afferent activity to a homogeneously connected population.

\section{The role of synaptic inhibition in GC spiking}

We found a striking increase in the I/E ratio across GC development that suggests synaptic inhibition becomes increasingly important for limiting spiking during GC maturation. Yet despite the lower I/E ratio, gabazine still increased the percentage of GCs that spiked and the average spiking probability at 4 weeks PTI. This result appears to conflict with studies by Marín-Burgin et al. 
(2012) and Li et al. (2012), which showed that blocking inhibition had no effect on the input strength required to generate $50 \%$ spiking. Several differences could underlie this discrepancy. First, we did not normalize stimulation intensities between cells but rather tested spiking probability across a range of stimulus intensities. We found that fEPSPs increased exponentially rather than linearly with stimulus intensity (data not shown) and that the population spike was not a sensitive indicator of stimulus strength since only a fraction of GCs spike regardless of stimulus intensity; thus, we simply used the EPSC amplitude as a measure of the input strength and normalized inhibition to excitation to account for differences in excitatory drive between cells. Second, our stimulus paradigm consisted of dual MML and OML stimulation to assess the integration of medial and lateral perforant path inputs, whereas prior studies primarily used single-pathway stimulation. Perhaps most importantly, we included nonspiking GCs in our analysis. Since inhibition suppresses spiking, nonspiking GCs are the most affected by gabazine. That a majority of GCs fail to spike in response to afferent stimulation is consistent with other slice studies using $\mathrm{Ca}^{2+}$ and voltage imaging (Coulter and Carlson, 2007; Yu et al., 2013). In principal, direct stimulation of GABAergic interneurons could overestimate the role of inhibition, but this is an unlikely confound since pure feedforward responses generated a similar range of I/E ratios that also differed between mature and immature GCs (Fig. 8). Together, our results show that GABAergic inhibition plays a role in GC excitability even in immature GCs.

The potential significance of inhibitory control of immature GC spiking is threefold. First, our results show that the participation of immature GCs in DG network activity is subject to modulation of GABAergic inhibition. Since GABA depolarizes GCs at all stages of their development (Staley and Mody, 1992; Chiang et al., 2012; Sauer et al., 2012), GABAergic inhibition is achieved both by shunting inhibition and the regulation of action potential threshold (Rojas et al., 2011). Excitatory effects of GABA depolarization could promote GC spiking, depending on the exact location and timing of synaptic GABA events (Chiang et al., 2012), but have yet to be demonstrated experimentally. Since synaptic inhibition is regulated by a myriad of neurotransmitters and modulators, inhibitory control of immature GC activation provides a mechanism for flexible regulation of immature GC activation under a variety of conditions. Second, synaptic inhibition not only suppresses excitability but can also lower the correlation of spiking in populations of neurons receiving coactivation (Middleton et al., 2012). Thus, the inhibition of immature and mature GCs could contribute to enhancing variability in the sparse population coding of the DG. Finally, synaptic inhibition is also expected to contribute to the window of excitatory integration conferred by dendritic passive membrane properties (Pouille and Scanziani, 2001; Schmidt-Hieber et al., 2007; Krueppel et al., 2011).
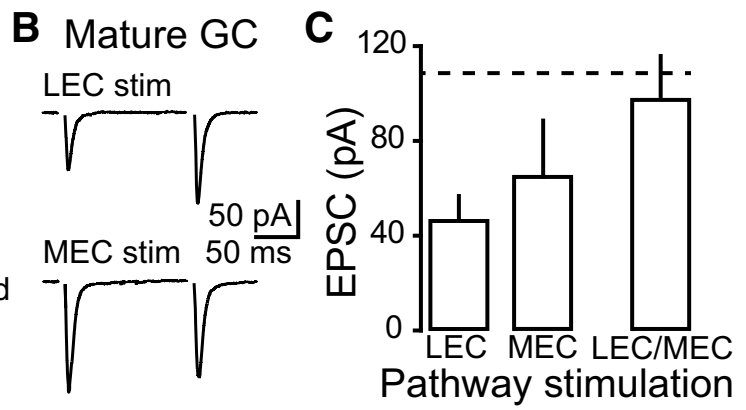

Pathway stimulation

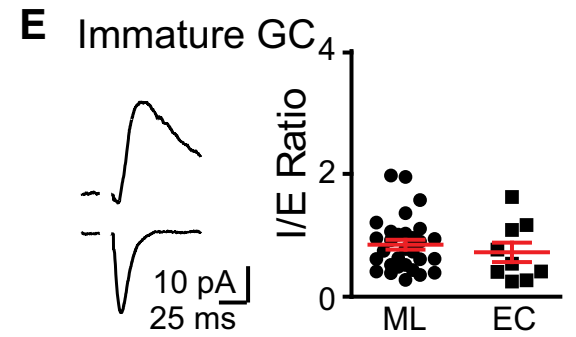

Figure 8. Reduced I/E ratios of immature GCs following EC stimulation (stim). $\boldsymbol{A}$, Schematic diagram of stimulation paradigm 24) was similar to that of MML/OML stimulation ( $n=32$ from Fig. $4 \mathrm{C}$ ) unpaired $t$ test, $p=0.9$. L Left Example of the //E ratio in an immature GC at 4 weeks PTI following MEC/LEC stimulation. Right, The I/E ratio from MEC/LEC stimulation ( $n=30$, from Fig. $6 D, F)$ was similar to that of MML/OML stimulation $(n=9)$; unpaired $t$ test, $p=0.5$.

Distinct mechanisms maintain sparse activation of immature and mature GCs

The decision to fire an action potential is determined by a combination of excitatory drive, intrinsic excitability, and synaptic inhibition. Our results suggest that the relative importance of these factors changes across GC maturation. GCs $\sim 3$ weeks of age had the highest input resistance, yet a relatively depolarized threshold for spiking and the lowest degree of excitatory innervation. Although insufficient excitatory drive prevented spiking in our stimulating paradigm, different stimulating protocols or recording conditions can recruit this highly excitable population (Mongiat et al., 2009). Conversely, the high degree of excitatory innervation assured that mature GCs were very likely to reach threshold in the absence of inhibition despite their lower input resistance. We thus conclude that spiking in very immature GCs is limited primarily by excitatory drive, whereas spiking in mature GCs is limited primarily by inhibition.

The determinants of spiking at intermediate stages are more complex. At 6 weeks PTI, GCs had higher input resistance and lower I/E ratio than mature GCs, yet similar spiking probability (Fig. 5E). Like mature GCs, spiking probability approached 1 when inhibition was blocked showing that inhibition strongly suppressed spiking at this stage. The low I/E ratio of spiking mature and 6-week-old GCs was associated with large EPSCs (at highest stimulus intensity; Table 1), suggesting that heterogeneous excitation contributes to the ratio at both stages (Pouille et al., 2009).

An unexpected result was that spiking in immature GCs did not correlate with input resistance, and, in fact, there was a trend for spiking cells to have a lower input resistance at each time interval (Table 1). This suggests that intrinsic properties other than input resistance promote spiking of immature GCs. For example, low-voltage activated $\mathrm{Ca}^{+}$channels in immature GCs 
A

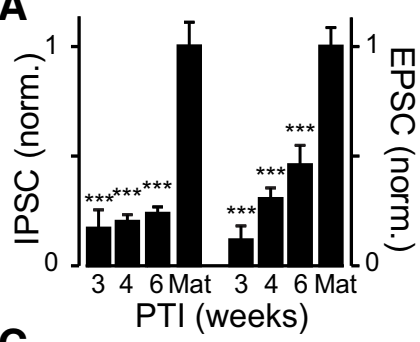

C

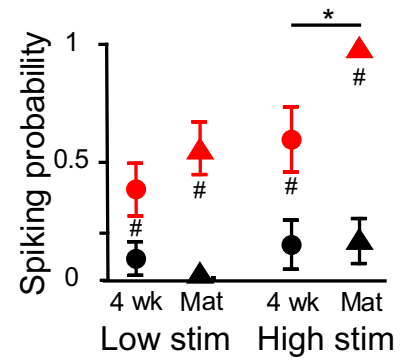

B
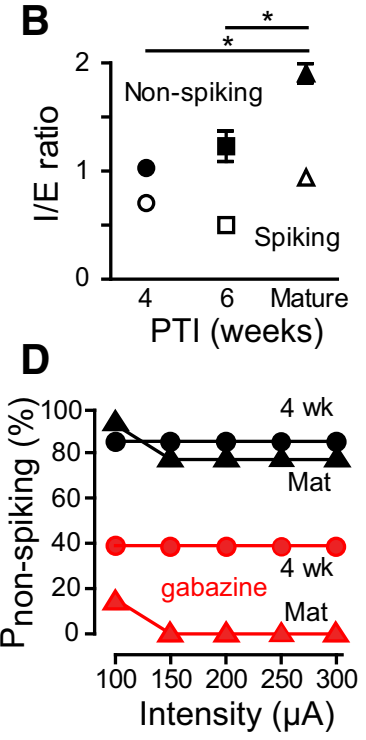

Figure 9. Distinct determinants of sparse spiking. $\boldsymbol{A}$, IPSC and EPSC amplitudes in immature GCs are significantly different from mature GCs. One-way ANOVA: $F_{(3,66)}=16.37, p<0.0001$ (IPSCS); $F_{(3,66)}=16.32, p<0.0001$ (EPSCS). Tukey's post-test, ${ }^{* * *} p<0.05$. IPSCs and EPSCs ( $n=15-32$ ) were normalized to averaged mature GCs currents. $\boldsymbol{B}$, The I/E ratio of nonspiking $\mathrm{GCs}$ increased with time. Solid symbols represent the average I/E ratio of nonspiking $\mathrm{GCS}$, and open symbols represent the average $\mathrm{I} / \mathrm{E}$ ratio for spiking $\mathrm{GCs}$ with all stimulus (stim) intensities combined: $S \times N S: F_{(1,304)}=49,5, p<0.0001 ; 4$ weeks $\times 6$ weeks $\times$ mature (Mat): $F_{(2,304)}=19.02, p<0.0001$; interaction: $F_{(2,304)}=4.5, p=0.012$. Tukey's post-test: NS 4 weeks $\times$ NS Mat; NS 6 weeks $\times$ NS Mat: ${ }^{*} p<0.05$. C, Gabazine increased the average spiking probability at all stimulus intensities. Data from cell-attached recordings in Figure 7 show the highest and lowest stimulus intensities, with the average spiking probability from spiking and nonspiking cells combined. Low stimulus intensity: control $\times$ gabazine: $F_{(1,24)}=32.3, p=$ 0.0007 . Tukey's post-test, $\# p<0.05$. At higher stimulus intensities, the spiking probability of 4 week PTI GCs is less than that of mature GCs in the presence of gabazine: two-way ANOVA: control $\times$ gabazine: $F_{(1,24)}=54.97, p=0.0001$; interaction: $F_{(1,24)}=4.57 ;{ }^{*} p=0.04$. D, The $P_{\text {nonspiking }}$ cells in control (black) and gabazine (red) shows that sparse activation (high $\left.P_{\text {nonspiking }}\right)$ is maintained by distinct mechanisms in mature (triangles) and 4 week PTI GCS (circles). This result was similar across all stimulation intensities, suggesting it did not depend on the number of activated fibers. Data are from cell-attached recordings in Figure 7.

can trigger $\mathrm{Ca}^{2+}$ spikes that boost initiation of $\mathrm{Na}^{+}$spikes in response to direct current injection (Schmidt-Hieber et al., 2004). We speculate that activation of voltage-dependent regenerative potentials also facilitates spiking in response to synaptic drive (Fig. $5 F$ ). Supporting this idea, we found that spiking 4 week PTI GCs generated slightly more spikes at successive current steps compared with nonspiking cells (not shown), despite the trend for a lower input resistance. Since input resistance is negatively correlated with dendrite length, the tendency for spiking GCs to have lower input resistance at each interval PTI also highlights the importance of excitatory drive that presumably depends on dendritic integration.

\section{Potential contribution of immature and mature GCs to DG network activity}

It is well established that the DG uses sparse population coding with only a small percentage of GCs activated in response to physiological stimuli (Jung and McNaughton, 1993; Chawla et al., 2005; Ramirez-Amaya et al., 2006; Kee et al., 2007; Stone et al., 2011; Neunuebel and Knierim, 2012). Although several studies using c-Fos as a marker of GC activation suggested preferential recruitment of immature GCs over mature GCs (RamirezAmaya et al., 2006; Kee et al., 2007), using strict measures of GC age revealed similar low levels of activation at every stage of mat-

uration (Stone et al., 2011). Our results showing that different mechanisms contribute to GC spiking at progressive developmental stages could allow GCs to process distinct components of entorhinal network activity rather than account for "more" or "less" of the DG neural representation. Reduced innervation combined with high intrinsic excitability and low I/E ratios predicts that immature GCs are highly responsive to select cortical inputs, whereas mature GCs with profuse innervation are minimally responsive to a broad array of cortical activity patterns.

\section{References}

Ambrogini P, Lattanzi D, Ciuffoli S, Agostini D, Bertini L, Stocchi V, Santi S, Cuppini R (2004) Morpho-functional characterization of neuronal cells at different stages of maturation in granule cell layer of adult rat dentate gyrus. Brain Res 1017:21-31. CrossRef Medline

Arruda-Carvalho M, Sakaguchi M, Akers KG, Josselyn SA, Frankland PW (2011) Post-training ablation of adult-generated neurons degrades previously acquired memories. J Neurosci 31:15113-15127. CrossRef Medline

Boulton CL, von Haebler D, Heinemann U (1992) Tracing of axonal connections by rhodamine-dextran-amine in the rat hippocampalentorhinal cortex slice preparation. Hippocampus 2:99-106. CrossRef Medline

Chancey JH, Adlaf EW, Sapp MC, Pugh PC, Wadiche JI, Overstreet-Wadiche LS (2013) GABA depolarization is required for experience-dependent synapse unsilencing in adult-born neurons. J Neurosci 33:6614-6622. CrossRef Medline

Chawla MK, Guzowski JF, Ramirez-Amaya V, Lipa P, Hoffman KL, Marriott LK, Worley PF, McNaughton BL, Barnes CA (2005) Sparse, environmentally selective expression of Arc RNA in the upper blade of the rodent fascia dentata by brief spatial experience. Hippocampus 15:579-586. CrossRef Medline

Chiang PH, Wu PY, Kuo TW, Liu YC, Chan CF, Chien TC, Cheng JK, Huang YY, Chiu CD, Lien CC (2012) GABA is depolarizing in hippocampal dentate granule cells of the adolescent and adult rats. J Neurosci 32:62-67. CrossRef Medline

Coulter DA, Carlson GC (2007) Functional regulation of the dentate gyrus by GABA-mediated inhibition. Prog Brain Res 163:235-243. CrossRef Medline

de Almeida L, Idiart M, Lisman JE (2009) The input-output transformation of the hippocampal granule cells: from grid cells to place fields. J Neurosci 29:7504-7512. CrossRef Medline

DeCarolis NA, Mechanic M, Petrik D, Carlton A, Ables JL, Malhotra S, Bachoo R, Götz M, Lagace DC, Eisch AJ (2013) In vivo contribution of nestin- and GLAST-lineage cells to adult hippocampal neurogenesis. Hippocampus 23:708-719. CrossRef Medline

Dieni CV, Chancey JH, Overstreet-Wadiche LS (2012) Dynamic functions of GABA signaling during granule cell maturation. Front Neural Circuits 6:113. CrossRef Medline

Espósito MS, Piatti VC, Laplagne DA, Morgenstern NA, Ferrari CC, Pitossi FJ, Schinder AF (2005) Neuronal differentiation in the adult hippocampus recapitulates embryonic development. J Neurosci 25:10074-10086. CrossRef Medline

Ewell LA, Jones MV (2010) Frequency-tuned distribution of inhibition in the dentate gyrus. J Neurosci 30:12597-12607. CrossRef Medline

Freund TF, Buzsáki G (1996) Interneurons of the hippocampus. Hippocampus 6:347-470. Medline

Ge S, Goh EL, Sailor KA, Kitabatake Y, Ming GL, Song H (2006) GABA regulates synaptic integration of newly generated neurons in the adult brain. Nature 439:589-593. CrossRef Medline

Gu Y, Arruda-Carvalho M, Wang J, Janoschka SR, Josselyn SA, Frankland PW, Ge S (2012) Optical controlling reveals time-dependent roles for adult-born dentate granule cells. Nat Neurosci 15:1700-1706. CrossRef Medline

Gupta A, Elgammal FS, Proddutur A, Shah S, Santhakumar V (2012) Decrease in tonic inhibition contributes to increase in dentate semilunar granule cell excitability after brain injury. J Neurosci 32:2523-2537. CrossRef Medline

Jung MW, McNaughton BL (1993) Spatial selectivity of unit activity in the hippocampal granular layer. Hippocampus 3:165-182. CrossRef Medline Kee N, Teixeira CM, Wang AH, Frankland PW (2007) Preferential incorpo- 
ration of adult-generated granule cells into spatial memory networks in the dentate gyrus. Nat Neurosci 10:355-362. CrossRef Medline

Krueppel R, Remy S, Beck H (2011) Dendritic integration in hippocampal dentate granule cells. Neuron 71:512-528. CrossRef Medline

Lagace DC, Whitman MC, Noonan MA, Ables JL, DeCarolis NA, Arguello AA, Donovan MH, Fischer SJ, Farnbauch LA, Beech RD, DiLeone RJ, Greer CA, Mandyam CD, Eisch AJ (2007) Dynamic contribution of nestin-expressing stem cells to adult neurogenesis. J Neurosci 27:1262312629. CrossRef Medline

Laplagne DA, Kamienkowski JE, Espósito MS, Piatti VC, Zhao C, Gage FH, Schinder AF (2007) Similar GABAergic inputs in dentate granule cells born during embryonic and adult neurogenesis. Eur J Neurosci 25:29732981. CrossRef Medline

Li Y, Aimone JB, Xu X, Callaway EM, Gage FH (2012) Development of GABAergic inputs controls the contribution of maturing neurons to the adult hippocampal network. Proc Natl Acad Sci U S A 109:4290-4295. CrossRef Medline

MacDermott AB, Westbrook GL (1986) Early development of voltagedependent sodium currents in cultured mouse spinal cord neurons. Dev Biol 113:317-326. CrossRef Medline

Marín-Burgin A, Mongiat LA, Pardi MB, Schinder AF (2012) Unique processing during a period of high excitation/inhibition balance in adultborn neurons. Science 335:1238-1242. CrossRef Medline

Markwardt SJ, Dieni CV, Wadiche JI, Overstreet-Wadiche L (2011) Ivy/ neurogliaform interneurons coordinate activity in the neurogenic niche. Nat Neurosci 14:1407-1409. CrossRef Medline

Middleton JW, Omar C, Doiron B, Simons DJ (2012) Neural correlation is stimulus modulated by feedforward inhibitory circuitry. J Neurosci 32: 506-518. CrossRef Medline

Mongiat LA, Esposito MS, Lombardi G, Schinder AF (2009) Reliable activation of immature neurons in the adult hippocampus. PLoS One 4:e5320. CrossRef Medline

Neunuebel JP, Knierim JJ (2012) Spatial firing correlates of physiologically distinct cell types of the rat dentate gyrus. J Neurosci 32:3848-3858. CrossRef Medline

Overstreet Wadiche L, Bromberg DA, Bensen AL, Westbrook GL (2005) GABAergic signaling to newborn neurons in dentate gyrus. J Neurophysiol 94:4528-4532. CrossRef Medline

Piatti VC, Davies-Sala MG, Espósito MS, Mongiat LA, Trinchero MF, Schinder AF (2011) The timing for neuronal maturation in the adult hippocampus is modulated by local network activity. J Neurosci 31:77157728. CrossRef Medline

Piatti VC, Ewell LA, Leutgeb JK (2013) Neurogenesis in the dentate gyrus: carrying the message or dictating the tone. Front Neurosci 7:50. CrossRef Medline

Pouille F, Marin-Burgin A, Adesnik H, Atallah BV, Scanziani M (2009) Input normalization by global feedforward inhibition expands cortical dynamic range. Nat Neurosci 12:1577-1585. CrossRef Medline

Pouille F, Scanziani M (2001) Enforcement of temporal fidelity in pyramidal cells by somatic feed-forward inhibition. Science 293:1159-1163. CrossRef Medline

Ramirez-Amaya V, Marrone DF, Gage FH, Worley PF, Barnes CA (2006) Integration of new neurons into functional neural networks. J Neurosci 26:12237-12241. CrossRef Medline
Rennó-Costa C, Lisman JE, Verschure PF (2010) The mechanism of rate remapping in the dentate gyrus. Neuron 68:1051-1058. CrossRef Medline

Rojas P, Akrouh A, Eisenman LN, Mennerick S (2011) Differential effects of axon initial segment and somatodendritic GABAA receptors on excitability measures in rat dentate granule neurons. J Neurophysiol 105:366-379. CrossRef Medline

Royer S, Zemelman BV, Losonczy A, Kim J, Chance F, Magee JC, Buzsáki G (2012) Control of timing, rate and bursts of hippocampal place cells by dendritic and somatic inhibition. Nat Neurosci 15:769-775. CrossRef Medline

Sauer JF, Strüber M, Bartos M (2012) Interneurons provide circuit-specific depolarization and hyperpolarization. J Neurosci 32:4224-4229. CrossRef Medline

Schmidt-Hieber C, Jonas P, Bischofberger J (2004) Enhanced synaptic plasticity in newly generated granule cells of the adult hippocampus. Nature 429:184-187. CrossRef Medline

Schmidt-Hieber C, Jonas P, Bischofberger J (2007) Subthreshold dendritic signal processing and coincidence detection in dentate gyrus granule cells. J Neurosci 27:8430-8441. CrossRef Medline

Snyder JS, Ferrante SC, Cameron HA (2012) Late maturation of adult-born neurons in the temporal dentate gyrus. PLoS One 7:e48757. CrossRef Medline

Staley KJ, Mody I (1992) Shunting of excitatory input to dentate gyrus granule cells by a depolarizing GABAA receptor-mediated postsynaptic conductance. J Neurophysiol 68:197-212. Medline

Stokes CC, Isaacson JS (2010) From dendrite to soma: dynamic routing of inhibition by complementary interneuron microcircuits in olfactory cortex. Neuron 67:452-465. CrossRef Medline

Stone SS, Teixeira CM, Zaslavsky K, Wheeler AL, Martinez-Canabal A, Wang AH, Sakaguchi M, Lozano AM, Frankland PW (2011) Functional convergence of developmentally and adult-generated granule cells in dentate gyrus circuits supporting hippocampus-dependent memory. Hippocampus 21:1348-1362. CrossRef Medline

Tozuka Y, Fukuda S, Namba T, Seki T, Hisatsune T (2005) GABAergic excitation promotes neuronal differentiation in adult hippocampal progenitor cells. Neuron 47:803-815. CrossRef Medline

Wang S, Scott BW, Wojtowicz JM (2000) Heterogenous properties of dentate granule neurons in the adult rat. J Neurobiol 42:248-257. CrossRef Medline

Williams PA, Larimer P, Gao Y, Strowbridge BW (2007) Semilunar granule cells: glutamatergic neurons in the rat dentate gyrus with axon collaterals in the inner molecular layer. J Neurosci 27:13756-13761. CrossRef Medline

Yu EP, Dengler CG, Frausto SF, Putt ME, Yue C, Takano H, Coulter DA (2013) Protracted postnatal development of sparse, specific dentate granule cell activation in the mouse hippocampus. J Neurosci 33:29472960. CrossRef Medline

Zhao C, Teng EM, Summers RG Jr, Ming GL, Gage FH (2006) Distinct morphological stages of dentate granule neuron maturation in the adult mouse hippocampus. J Neurosci 26:3-11. CrossRef Medline

Zhao S, Zhou Y, Gross J, Miao P, Qiu L, Wang D, Chen Q, Feng G (2010) Fluorescent labeling of newborn dentate granule cells in GAD67-GFP transgenic mice: a genetic tool for the study of adult neurogenesis. PLoS One 5:e12506. CrossRef Medline 